\title{
Avaliação de alternativas direcionadas à redução do consumo de água potável em residências: estudo de caso em Caruaru, PE, Brasil
}

Evaluation of alternatives for reducing household potable
water consumption: case study in Caruaru, PE, Brazil

Lyanne Cibely Oliveira de Sousa

Saulo de Tarso Marques Bezerra

Jose Matheus Bezerra dos Santos Amorim

Isaura Macêdo Alves

Armando Dias Duarte

${ }^{1}$ Lyanne Cibely Oliveira de Sousa ${ }^{1}$ Universidade Federal de Pernambuco Caruaru - PE - Brasil

${ }^{2}$ Saulo de Tarso Marques Bezerra 'Universidade Federal de Pernambuco Caruaru - PE - Brasil

${ }^{3}$ Jose Matheus Bezerra dos Santos Amorim ${ }^{3}$ Instituto Brasileiro de Geografia e Estatística Caruaru - PE - Brasil

${ }^{4}$ Isaura Macêdo Alves ${ }^{4}$ Universidade Federal de Pernambuco Caruaru - PE - Brasil

${ }^{5}$ Armando Dias Duarte ${ }^{5}$ Universidade Federal de Pernambuco Recife - PE - Brasil

Recebido em 26/07/19 Aceito em 11/10/19

\section{Resumo \\ $\mathbf{E}$} m um cenário de crise hídrica, como o vivenciado pelo Agreste Brasileiro nos últimos anos, a sustentabilidade do abastecimento de água tem sido tema de inúmeras investigações. Nesse sentido, esta pesquisa abordou o estudo da implantação hipotética de alternativas tecnológicas direcionadas à redução do consumo de água potável em residências de Caruaru, PE. As alternativas adotadas foram avaliadas segundo uma perspectiva multicritério, considerando critérios ambientais, técnicos, econômicos e sociais, identificados por meio de projetos, pesquisas de mercado e entrevistas com moradores e especialistas. Com a aplicação do método Promethee II, foi possível verificar que a implantação de equipamentos economizadores seria a alternativa mais indicada para a região. A redução no consumo de água dessa alternativa foi de $29,11 \%$, enquanto o tempo de retorno do investimento foi estimado em 16 meses. O elevado prazo para recuperar o capital das demais alternativas evidencia a necessidade de políticas governamentais que ofereçam incentivos financeiros à população, de modo a impedir que as condições socioeconômicas da região sejam o principal entrave para a adoção de práticas de conservação dos recursos hídricos.

Palavras-chave: Gestão de recursos hídricos. Captação de água de chuva. Equipamentos economizadores. Reúso de águas cinza. Promethee.

\begin{abstract}
In a scenario of water crisis, such as that experienced by the Brazilian Agreste region in recent years, the sustainability of water supply has been the aim of several investigations. This research project involved the study of the hypothetical implementation of technological alternatives for reducing household potable water consumption in Caruaru, PE. The alternatives were evaluated from a multicriteria perspective. That perspective takes into account environmental, technical, economic and social criteria, which are identified through designs, market research and interviews with residents and experts. With the application of the multicriteria method Promethee II, it was possible to verify that the implementation of water-saving devices is the most suitable alternative for the region. This alternative promotes a $29.11 \%$ reduction in water consumption, while the payback period was estimated at 16 months. The long term required to recover the capital in the other alternatives highlights the need for government policies offering financial incentives to the population, preventing the region's socioeconomic conditions from being the main obstacle for the adoption of water resources conservation practices.
\end{abstract}

Keywords: Water resource management. Rainwater. Water-saving devices. Greywater reuse. Promethee.

SOUSA, L. C. O. de; BEZERRA, S. de T. M.; AMORIM, J. M. B. dos S.; ALVES, I. M.; DUARTE, A. D. Avaliação 465 de alternativas direcionadas à redução do consumo de água potável em residências: estudo de caso em Caruaru, PE, Brasil.

Ambiente Construído, Porto Alegre, v. 20, n. 4, p. 465-487, out./dez. 2020.

ISSN 1678-8621 Associação Nacional de Tecnologia do Ambiente Construído.

http://dx.doi.org/10.1590/s1678-86212020000400483 


\section{Introdução}

A demanda urbana de água mundial vem crescendo rapidamente em virtude do aumento populacional, do desenvolvimento econômico e da alta taxa de urbanização; por outro lado, a limitação dos recursos hídricos disponíveis faz aumentar a competição entre usos da água e reduz o acesso à água de boa qualidade, tornando o fornecimento aos centros urbanos um grande desafio para a gestão de recursos hídricos (SHARMA; VAIRAVAMOORTHY, 2009).

A progressiva deterioração dos recursos hídricos e o agravamento dos conflitos entre os diversos usuários impulsionam discussões sobre a situação atual e o futuro da água em todo o mundo. Sua disponibilidade é abundante em escala global, porém, em contextos regionais, devido às características naturais e climáticas, podem ser escassos e não se encontram uniformemente distribuídos. É urgente a avaliação de incertezas relacionadas aos recursos sustentáveis de gerenciamento de água no contexto da mudança climática (WANG et al., 2016).

O abastecimento da população deve, então, ocorrer em concordância com a disponibilidade dos mananciais. De tal modo, os responsáveis pela gestão dos recursos hídricos enfrentam o problema de satisfazer a necessidade da população e, ao mesmo tempo, controlar os níveis dos mananciais de forma que esses possam manter uma capacidade suficiente para sustentar o abastecimento ao longo do tempo. Esse problema assinala-se como uma decisão estratégica entre a oferta e a demanda de água.

A nova fase de gestão de recursos hídricos está baseada na avaliação integrada da gestão de oferta e demanda de água. A tradicional ótica de expansão da oferta de água está se tornando tecnicamente e economicamente inviável, o que implica a necessidade da adoção de modelos modernos, de caráter multidisciplinar e participativo, que agreguem o gerenciamento da demanda de água à gestão de recursos hídricos. Em acréscimo à tradicional solução para a "falta d'água" nos sistemas - expansão da oferta -, surgiu no âmbito da gestão o conceito de gestão da demanda.

A gestão da demanda de água é definida neste trabalho como qualquer ação que reduz a quantidade de água consumida ou permite que a água seja utilizada de forma mais eficiente. Na prática, consiste na adoção de medidas que visam ao uso racional de água, sem prejuízo à higiene e ao conforto à população. Esse conceito, quando consolidado, colabora na redução da escassez e da vulnerabilidade hídrica, buscando a sustentabilidade dos recursos hídricos para as gerações atual e futura.

A avaliação de alternativas de gerenciamento da demanda é primordial na região do Agreste de Pernambuco, Brasil, onde as condições climáticas, aliadas a sistemas de abastecimento de água obsoletos e crescimento populacional acelerado, resultam no surgimento de graves problemas de abastecimento, que dificultam o atendimento das demandas quantitativas e qualitativas da população. Devido ao colapso do principal reservatório da região, a população da cidade de Caruaru, PE, vem enfrentando um rodízio severo no abastecimento de água nos últimos anos. Para o mês de setembro deste ano, a Companhia Pernambucana de Saneamento (Compesa) definiu um calendário que estabeleceu cinco dias com fornecimento de água e quinze dias sem água. A população frequentemente complementa o seu abastecimento com a compra de água comercializada por caminhões-pipa.

O regime intermitente de abastecimento de água em Caruaru certamente tem maior impacto nas comunidades de baixa renda, as quais não podem contratar, devido a limitações econômicas, serviços privados com a mesma frequência que a parcela da população de melhor renda. Consequentemente, a implementação de alternativas de gerenciamento da demanda promove maior acessibilidade à água em comunidades de interesse social.

Nesse contexto, esta pesquisa se insere no conjunto de estudos que visam contribuir para discussões voltadas à redução do desperdício, conservação e uso sustentável da água potável na região do Agreste de Pernambuco. Entende-se que a adoção de uma escala de bairro é apropriada para o estudo técnico, financeiro e ambiental das alternativas de gerenciamento da demanda, analisando detalhadamente ações de combate ao desperdício quantitativo, como, por exemplo, a adoção de equipamentos economizadores, e a utilização de fontes alternativas, como reúso de água cinza e captação de chuva. O objetivo principal desta pesquisa foi hierarquizar, por meio do método multicritério Promethee II, alternativas tecnológicas direcionadas à redução do consumo de água potável em residências localizadas em um bairro de classe média baixa de Caruaru, PE.

O Promethee (Preference Ranking Organization Method for Enrichment Evaluation) foi concebido pelo professor Jean-Pierre Brans (BRANS, 1982) em Bruxelas, Bélgica. Esse método possui recursos de modelagem de preferências mais flexíveis e maior facilidade de uso que outros métodos, como o Electre

466 Sousa, L. C. O. de; Bezerra, S. de T. M.; Amorim, J. M. B. dos S.; Alves, I. M.; Duarte, A. D. 
(MARESCHAL, 1983). O Promethee II foi escolhido por ser considerado um método multicritério não compensatório, que permite um ranqueamento total das alternativas, de fácil entendimento e aplicabilidade, além de apresentar parâmetros com significados físicos ou econômicos de rápida assimilação pelos decisores e analistas. Por ser um método de sobreclassificação, busca a alternativa mais indicada por meio da comparação par a par entre todas as opções analisadas, com um paradigma diferente de outras abordagens, que usualmente agregam critérios por meio de uma função aditiva.

O método é adequado para o objetivo proposto, pois permite a hierarquização de alternativas tecnológicas por meio da identificação prévia de critérios e alternativas. O Promethee é amplamente adotado pela comunidade cientifica em diversas áreas, como, por exemplo, construção civil (POLAT et al., 2016; MORKUNAITE et al., 2019), drenagem urbana (ARAÚJO et al., 2017; BABAEI; GHAZAVI; ERFANIA, 2018), geração de energia (WU et al., 2017; ANDREOPOULOU et al., 2018), hidráulica (BRANKOVIC; MARKOVIC; NIKOLIC, 2018; KHORAMSHOKOOH et al., 2018), hidrologia (VULEVIĆ; DRAGOVIĆ, 2017; INAMDAR et al., 2018), saneamento (MARQUES; CUNHA; SAVIUC, 2017; SAPKOTA et al., 2018).

\section{Área de estudo}

O município de Caruaru (Figura 1) está localizado na Mesorregião Agreste e na Microrregião Vale do Ipojuca do Estado de Pernambuco, limitando-se a norte com Toritama, Vertentes e Taquaritinga do Norte, a sul com Altinho e Agrestina, a leste com Bezerros e Riacho das Almas, e a oeste com Brejo da Madre de Deus e São Caitano. A área do município ocupa $928,1 \mathrm{~km}^{2}$ e representa $0,94 \%$ do Estado de Pernambuco. A sede do município tem uma altitude aproximada de $554 \mathrm{~m}$ e coordenadas geográficas de $8^{\circ} 17^{\prime} 00^{\prime}$ ' de latitude sul e $35^{\circ} 58^{\prime} 34^{\prime}$ ' de longitude oeste, distando $140,7 \mathrm{~km}$ da capital, cujo acesso é realizado pela BR232.

Por estar incluída no Polígono das Secas, Caruaru apresenta um regime pluviométrico marcado por extrema irregularidade de chuvas, no tempo e no espaço. A escassez de água constitui um forte entrave ao desenvolvimento socioeconômico da região, bem como à subsistência da população. A cidade encontra-se inserida nos domínios das bacias hidrográficas dos rios Ipojuca e Capibaribe. Seus principais tributários são: o rio Capibaribe e os riachos: Tabocas, Caiçara, Borba, da Onça, Olho D’água, Mandacaru do Norte, Carapotós, São Bento, Curtume e Taquara. Todos os cursos de água no município têm regime de escoamento intermitente.

Figura 1 - Localização da área de estudo

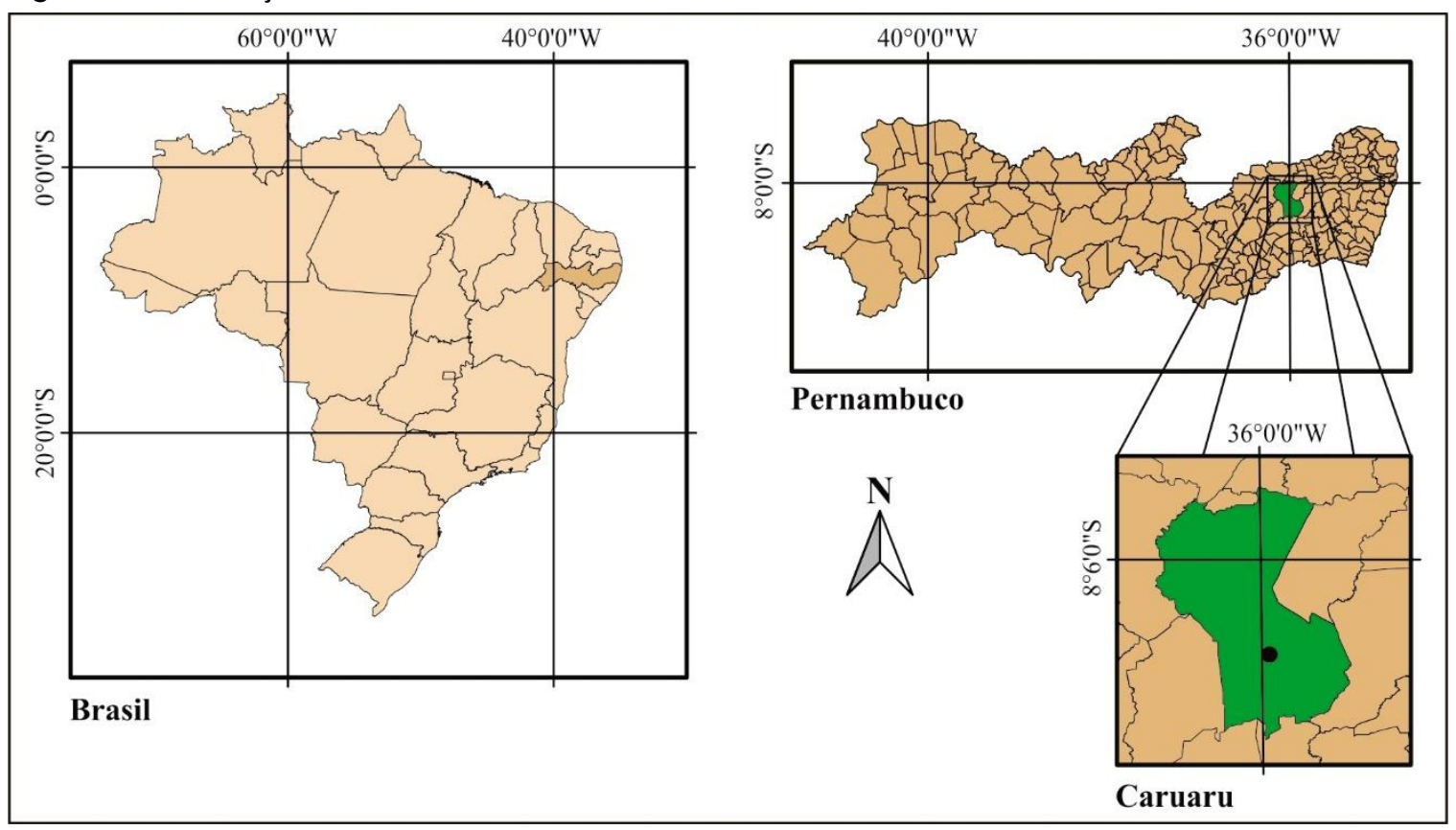

Fonte: Santana et al. (2019). 
A geologia subjacente da região é caracterizada por embasamento cristalino de baixa condutividade hidráulica e baixa capacidade de infiltração. As más propriedades hidráulicas do porão cristalino subjacente significam que o armazenamento e a extração de águas subterrâneas estão limitados a depósitos de aluvião no leito de rios (LAFAYETTE et al., 2019).

A pesquisa abordou o estudo de alternativas tecnológicas para o gerenciamento da demanda de água potável em uma escala micro, adotando como área de estudo o Residencial Caruá (Figura 2). Esse conjunto habitacional possui 248 residências domiciliares de baixo padrão com características similares entre si, que foram construídas com recursos do programa Minha Casa, Minha Vida. Em virtude de o residencial ser novo, a maioria das edificações não foi modificada ou reformada pelos moradores, a planta baixa da residência "padrão" (Figura 3) corresponde ao projeto original das habitações, que possui $160 \mathrm{~m}^{2}$ de terreno e $48 \mathrm{~m}^{2}$ de área construída.

\section{Metodologia}

A metodologia pode ser resumida conforme o esquema mostrado na Figura 4.

\section{Definição do objetivo, critérios e alternativas}

Foram adotadas alternativas tecnológicas de gerenciamento da demanda urbana de água mais citadas pela literatura que podem ser aplicadas em residências. O uso de equipamentos economizadores, captação de água de chuva e reúso de águas cinza têm sido avaliados frequentemente como alternativas tecnológicas para a promoção de economia de água potável. Pesquisas avaliaram o uso de equipamentos economizadores (KALBUSCH; GHISI, 2016; BERGER et al., 2017), da água de chuva (GOMEZ; TEIXEIRA, 2017; SEVERIS et al., 2019), em águas cinza (JUAN; CHEN; LIN, 2016; WANJIRU; XIA, 2017), ou a combinação dessas (MARINOSKI; GHISI, 2019; WU et al., 2019). O estudo considerou como alternativas associadas a aplicação conjunta de equipamentos economizadores + captação de água de chuva e equipamentos economizadores + reúso de águas cinza. A Figura 5 apresenta o fluxograma geral do modelo multicritério, apontando o objetivo, critérios e alternativas considerados na pesquisa.

Figura 2 - Planta baixa do Residencial Caruá, Caruaru, PE

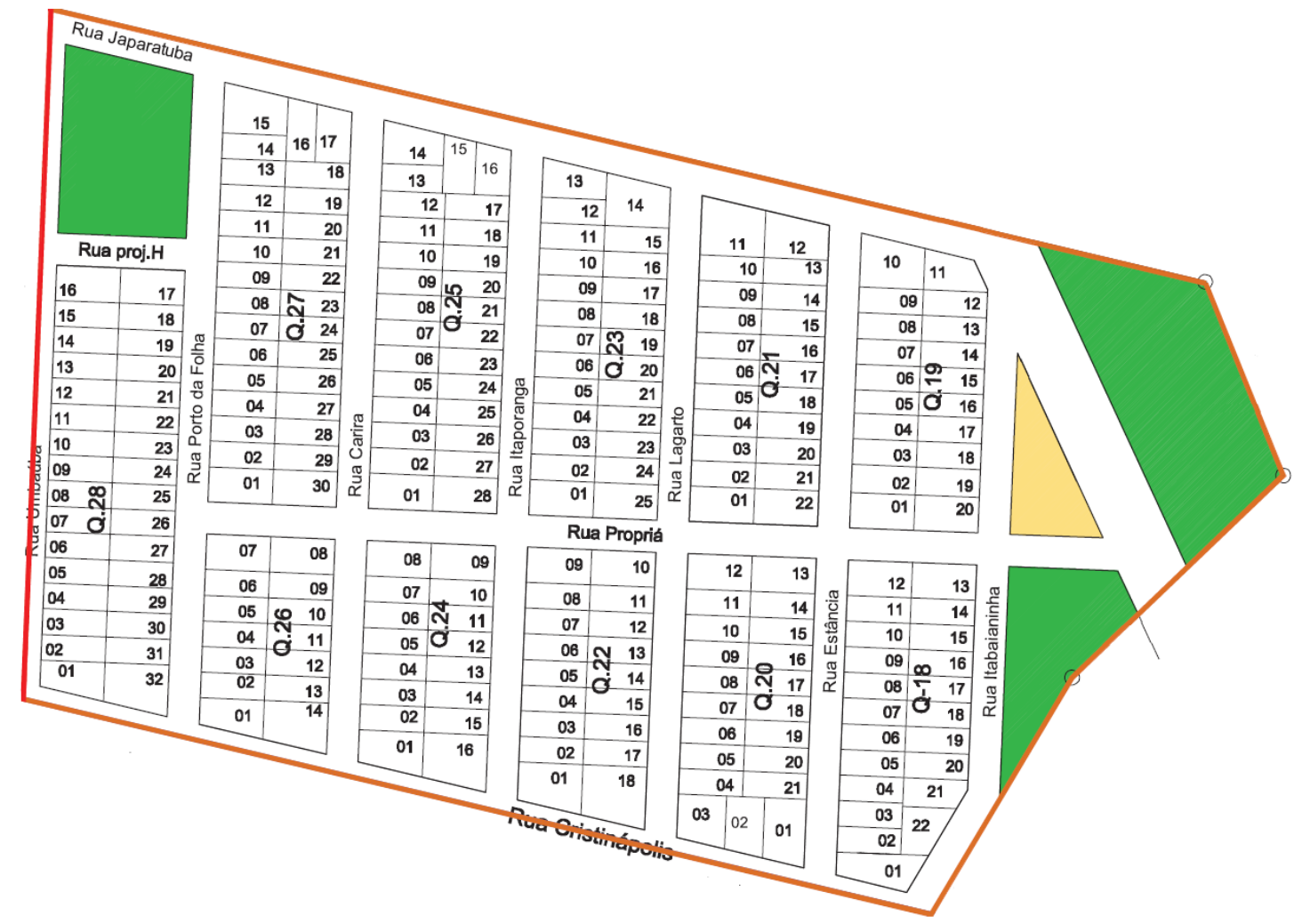

468 Sousa, L. C. O. de; Bezerra, S. de T. M.; Amorim, J. M. B. dos S.; Alves, I. M.; Duarte, A. D. 
Figura 3 - Planta baixa da residência padrão

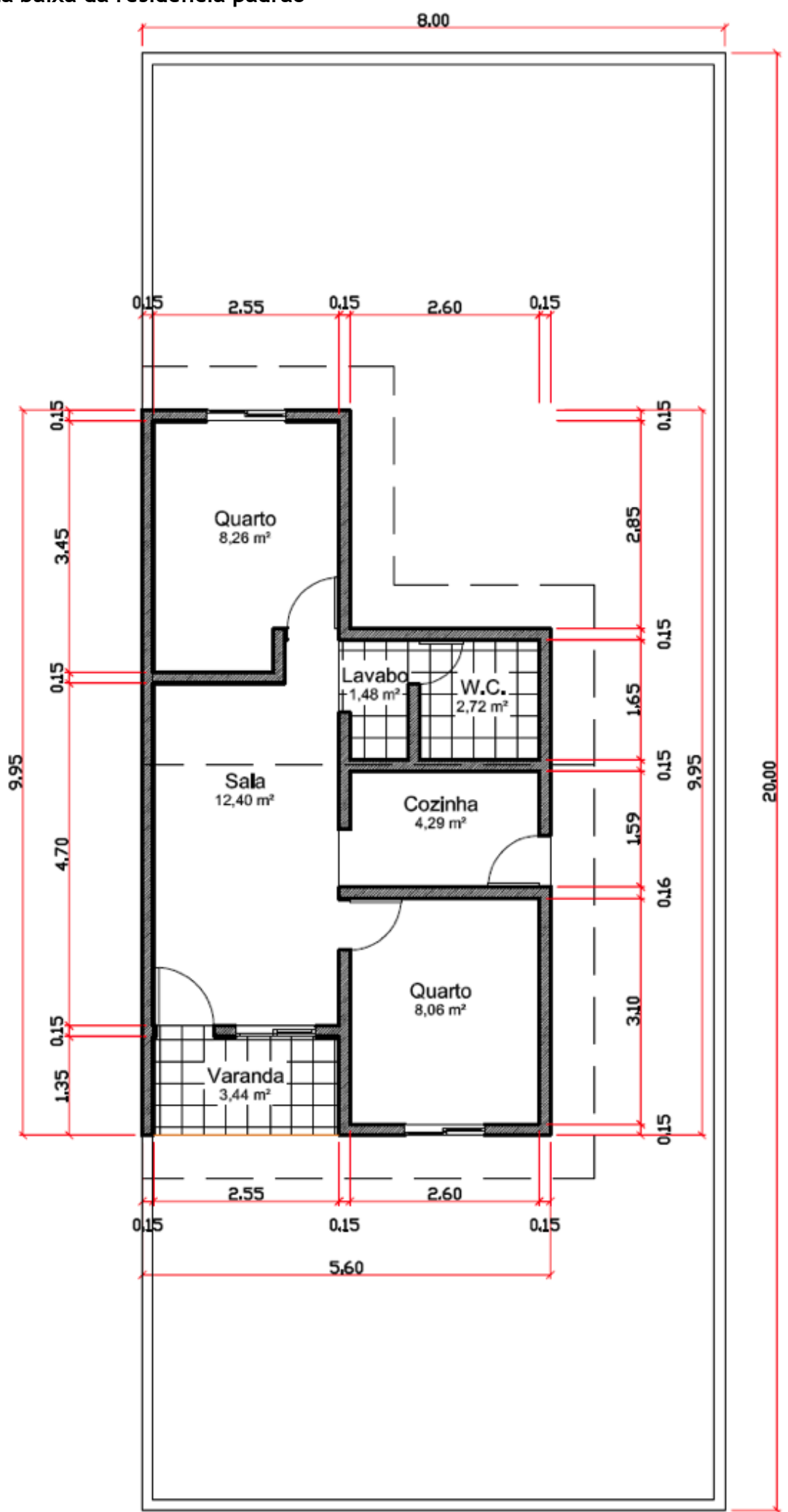


Figura 4 - Esquema de estruturação da pesquisa

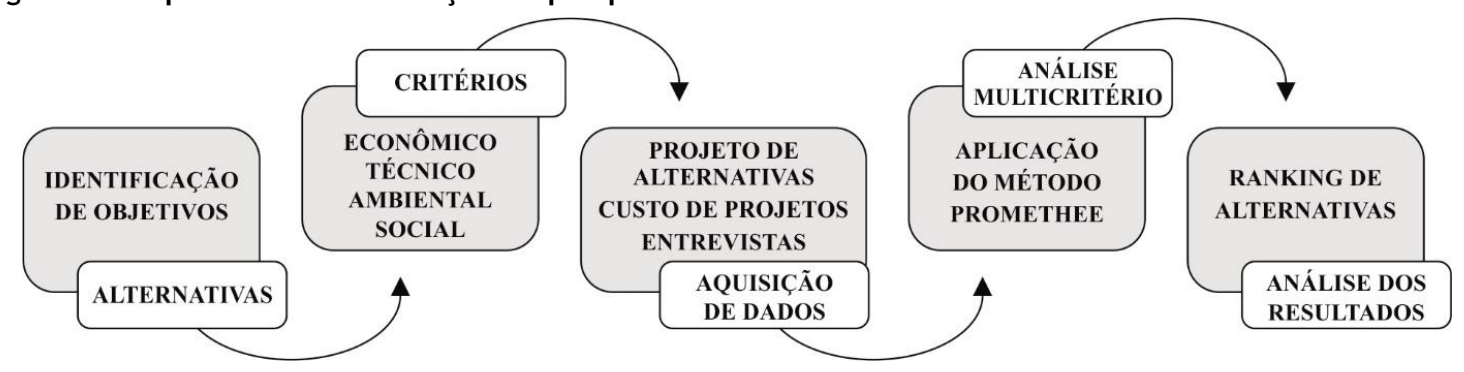

Figura 5 - Objetivo, critérios e alternativas do modelo multicritério

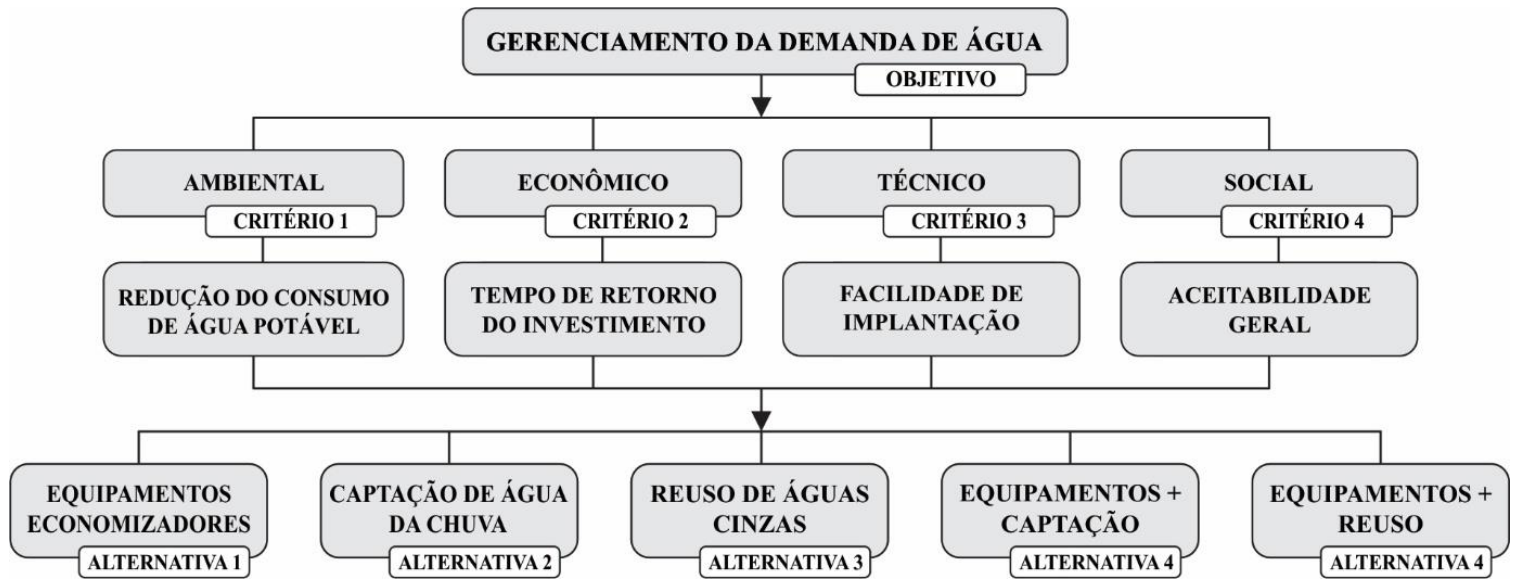

\section{Aplicação do método Promethee II}

Dentre os métodos que se baseiam na relação de sobreclassificação, o Promethee II, do tipo problemática de ordenação e de natureza não compensatória, foi a versão selecionada para aplicação neste estudo. A principal vantagem do método é a facilidade da obtenção de informações claras, que podem ser gerenciadas pelos decisores, como também pelos analistas. Para aplicação do método são necessários os seguintes procedimentos:

(a) definir uma matriz de decisão contendo as alternativas e critérios (Figura 5);

(b) definir os parâmetros da avaliação intracritério;

(c) definir os pesos relativos a cada um dos critérios;

(d) calcular o grau de sobreclassificação;

(e) calcular os fluxos de sobreclassificação positivos e negativos para cada uma das alternativas; e

(f) calcular o fluxo de sobreclassificação líquido.

A primeira etapa do processo de aplicação do Promethee II é denominada de avaliação intracritério, refere-se ao estabelecimento da função de preferência, limiar preferência $(p)$ e do limiar de indiferença $(q)$, de acordo com a predileção do decisor. Com base no tipo dos dados coletados e nas características dos subcritérios estabelecidos, foram determinadas as funções de preferência e os valores do parâmetro $p$ (limiar) foram determinadas para cada critério (Tabela 1). Essas funções representam o comportamento ou a atitude do decisor frente às diferenças provenientes da comparação par a par entre as alternativas, para um dado critério, indicando a intensidade da preferência da diferença. $p$ é o limite de preferência, que representa o menor valor para a função de preferência acima do qual existe uma preferência estrita, enquanto $q$ é o limite de indiferença, definido como o maior valor para a função de preferência abaixo do qual existe uma indiferença. 
Tabela 1 - Função de preferência dos critérios

\begin{tabular}{c|c|c|c|c}
\hline Critério & Subcritério & Intenção & Função & Parâmetro $\boldsymbol{p}$ \\
\hline Ambiental & $\begin{array}{c}\text { Redução de consumo de } \\
\text { água potável }\end{array}$ & Maximizar & III - Limiar de preferência & $5 \%$ \\
\hline Econômico & $\begin{array}{c}\text { Tempo de retorno do } \\
\text { investimento }\end{array}$ & Minimizar & III - Limiar de preferência & 2 anos \\
\hline Técnico & Facilidade de implantação & Maximizar & I - Critério usual & - \\
\hline Social & Aceitabilidade geral & Maximizar & III - Limiar de preferência & 0,20 \\
\hline
\end{tabular}

Para os critérios 1, 2 e 4 (redução de consumo de água potável, tempo de retorno do investimento e aceitabilidade geral), adotou-se a função Tipo III - Limiar de preferência, considerando que a preferência do decisor por uma alternativa em relação a outra cresce linearmente com a diferença de desempenho entre essas. Sendo assim, uma alternativa é considerada estritamente preferível a outra, a partir de um determinado limiar de preferência $(p)$. Para o critério 3 (facilidade de implantação), de acordo com De Keyser e Peeters (1996), a função mais apropriada é a Tipo I - Critério usual. As funções adotadas não possuem limite de indiferença $(q)$.

Empregando a função de preferência, as alternativas podem ser hierarquizadas pelo resultado líquido definido por meio das comparações par a par entre as alternativas, determinando, ao final da aplicação, o conjunto classificado por um indicador multicritério ordenado segundo os critérios e pesos estabelecidos, da menor para a maior potencialidade. O emprego do Promethee II permite a captação da amplitude das diferenças entre as avaliações de cada um dos critérios, oferecendo dois graus de liberdade ao decisor, um relativo à seleção do tipo de função de preferência, e outro à definição dos limiares (BRANS; MARESCHAL, 1994).

A etapa seguinte do método, denominada de avaliação intercritério, refere-se à agregação dos critérios por meio de uma combinação quantitativa, na qual os decisores avaliam a importância relativa de cada critério pela atribuição de pesos. Quanto maior o peso, maior sua importância, de acordo com a preferência do decisor. Os pesos foram definidos através da consulta a seis pesquisadores da Universidade Federal de Pernambuco com larga experiência na implantação das alternativas avaliadas, por meio do método swing weighting. Nas entrevistas, os especialistas atribuíram valores de pesos aos critérios, de modo que o valor da soma de todos os pesos correspondesse a 1. Com esses dados, os pesos foram definidos como a média para cada valor dado pelos entrevistados (Tabela 2).

No processo de análise, decompõe-se o objetivo em critérios e as comparações entre as alternativas são realizadas no último nível de decomposição e aos pares, pelo estabelecimento de uma relação ditada pela preferência dos agentes decisores, que se dá conforme a Figura 6. A comparação das alternativas permite a obtenção do grau de sobreclassificação, que estabelece o quanto cada uma se sobressai em relação a outra.

O grau de sobreclassificação de $a$ sobre $b[\pi(a, b)]$ é realizado de acordo com a Equação 1 . O valor de $F_{i}(a$, $b$ ) é determinado de forma individual para cada critério. A escolha das funções de preferência deve considerar o modo como o decisor avalia cada critério, transformando a diferença entre duas avaliações, em um determinado critério, para um valor real entre 0 e 1 .

$p(a, b)=\stackrel{\text { à }}{n} w_{i}^{\prime} F_{i}(a, b)$

Eq. 1

Onde:

$\pi(a, b)$ é o grau de sobreclassificação de $a$ sobre $b$;

$w_{i}$ é o peso do critério $i$; e

$F_{i}(a, b)$ é a função de preferência, que representa a diferença de desempenho das alternativas $a$ e $b$ em relação ao critério $i$.

Posteriormente, obtêm-se os fluxos de sobreclassificação positivos $\left(\Phi^{+}\right)$e negativos $\left(\Phi^{-}\right)$, conforme as Equações 2 e 3, respectivamente, para cada uma das alternativas, expressando o quanto a alternativa $a$ supera as demais $\left(\Phi^{+}\right)$e o quanto a alternativa $a$ foi superada pelas demais alternativas $\left(\Phi^{-}\right)$. 


$$
\begin{aligned}
& \Phi^{+}(a)=\frac{1}{n-1} \sum_{b \in A} \pi(a, b) \\
& \Phi^{-}(a)=\frac{1}{n-1} \sum_{b \in A} \pi(b, a)
\end{aligned}
$$

Desse modo, cada fluxo representa o somatório do grau de preferência de cada comparação par a par. Os valores variam de 0 a 1 , de modo que, quanto mais próximo a 1 , melhor é a alternativa para $\Phi^{+}$e pior é a alternativa para $\Phi^{-}$. O fluxo de sobreclassificação líquido $(\Phi)$ representa a diferença entre os fluxos de sobreclassificação positivos e negativos (Equação 4), gerando uma ordem completa com o resultado final de cada alternativa.

$\Phi(a)=\Phi^{+}(a)-\Phi^{-}(a)$

Sendo $a$ e $b$ alternativas, têm-se as seguintes relações:

(a) a alternativa $a$ é preferível à alternativa $b$ se $\Phi(a)>\Phi(b)$; e

(b) a alternativa $a$ é indiferente à alternativa $b$ se $\Phi(a)=\Phi(b)$.

Dessa forma, quanto maior o valor de $\Phi$ de uma alternativa, melhor a classificação na ordenação final promovida pelo modelo.

Uma análise de sensibilidade foi realizada para averiguar a robustez do método quanto às incertezas existentes no processo de atribuição dos pesos dos critérios, especialmente no que diz respeito ao grau de "importância" dos critérios. A primeira análise considerou que todos os pesos são iguais, enquanto as demais adotaram um acréscimo $6 \%$ no peso de cada critério, redistribuindo os demais valores de modo que o somatório dos pesos se mantenha igual a um.

Tabela 2 - Pesos relativos aos critérios

\begin{tabular}{c|c|c}
\hline Critério & Subcritério & Peso \\
\hline Ambiental & Redução de consumo de água potável & 0,37 \\
Econômico & Tempo de retorno do investimento & 0,28 \\
Técnico & Facilidade de implantação & 0,18 \\
Social & Aceitabilidade geral & 0,17 \\
\hline
\end{tabular}

Figura 6 - Esquema para aplicação do método

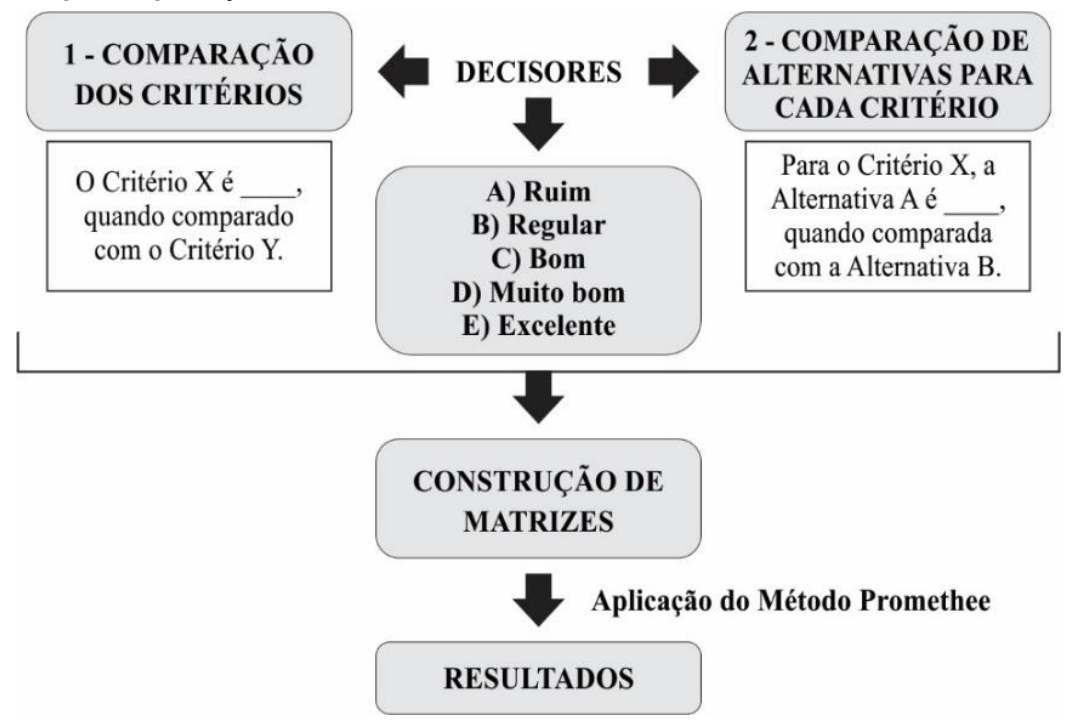

472 Sousa, L. C. O. de; Bezerra, S. de T. M.; Amorim, J. M. B. dos S.; Alves, I. M.; Duarte, A. D. 


\section{Avaliação de alternativas}

O estudo avaliará o emprego das principais alternativas tecnológicas aplicadas em residências unifamiliares, individualmente ou em conjunto, são essas:

(a) A1 - equipamentos economizadores;

(b) A2 - captação de água de chuva;

(c) A3 - reúso de águas cinza;

(d) A4 - equipamentos economizadores + captação de água de chuva; e

(e) A5 - equipamentos economizadores + reúso de águas cinza.

A alternativa A1 considera que os dispositivos convencionais da instalação hidráulica da residência serão substituídos por equipamentos de baixo consumo (economizadores), enquanto a água advinda dos sistemas de reúso de águas cinza e captação de água de chuva foi direcionada exclusivamente para uso em descargas de bacias sanitárias (uso não potável). As informações requeridas pela análise multicritério foram definidas com dados primários obtidos através de pesquisas de mercado no comercio local, projetos de engenharia, consultas à literatura e aplicação de questionários.

Para realização das entrevistas em campo, um questionário (Quadro 1) foi elaborado visando quantificar a aceitabilidade geral da população para cada alternativa, de forma a integrar cada entrevistado com o tema da pesquisa. Os projetos de engenharia - sistema de captação de água de chuva e sistema de reúso de águas cinza - foram desenvolvidos para o modelo de residência padrão do Residencial Caruá. Todo o material necessário para possível implantação dos projetos foi listado, apresentando os valores médios de cada alternativa de gerenciamento de água utilizada no estudo (aparelhos poupadores, reúso e captação de água de chuva).

\section{Critério 1: redução de consumo de água potável}

As características dos equipamentos são dadas na Tabela 3 (informações retiradas de catálogos de fabricantes), enquanto a Tabela 4 mostra o percentual médio de consumo de cada aparelho em uma residência. O ganho ambiental com a instalação de equipamentos economizadores será contabilizado por meio da redução do consumo de água potável fornecido pela concessionária.

O projeto de captação de água de chuva foi composto por: sistema de captação; desvio para descarte dos detritos e impurezas das primeiras descargas modelo DesviUFPE (CARVALHO et al., 2017); reservatório inferior; sistema de bombeamento; reservatório superior e a distribuição. Desse modo, o acúmulo de água de chuva será dado por meio da adição de mais um reservatório superior e um inferior. A água acumulada no reservatório inferior será bombeada para o reservatório superior e destinada para a utilização em descargas de bacias sanitárias. O dimensionamento dos reservatórios foi realizado por meio do Método da Simulação, descrito na NBR 15527 (ABNT, 2007). Como o índice pluviométrico é baixo, o reservatório foi dimensionado de modo que a sua capacidade não impôs restrição ao acumulo de água. De acordo com o método citado, o volume resultante foi $1.341 \mathrm{~m}^{3}$. Com isso, adotou-se um reservatório de polietileno de 1.000 litros (apoiado) e um de 500 litros (elevado). O volume mensal captado foi definido pela Equação 5, que é função da área do telhado, de características da composição material do telhado e da precipitação da região. Os demais itens foram dimensionados seguindo as diretrizes das seguintes normas técnicas da ABNT:

(a) NBR 10844 - Instalações prediais de águas pluviais (ABNT, 1989); e

(b) NBR 5626 - Instalação predial de água fria (ABNT, 1998).

$V=P \times A \times C \times \eta$

Onde:

$V$ é o volume captado no período considerado;

$P$ é a precipitação no período considerado;

$A$ é a área em projeção do telhado, que corresponde a $61 \mathrm{~m}^{2}$;

$C$ é o coeficiente de runoff, igual a 0,95 ; e

$\eta$ é o fator para contabilizar o descarte dos detritos e impurezas das primeiras descargas, igual a 0,89 . 


\section{Quadro 1 - Questionário}

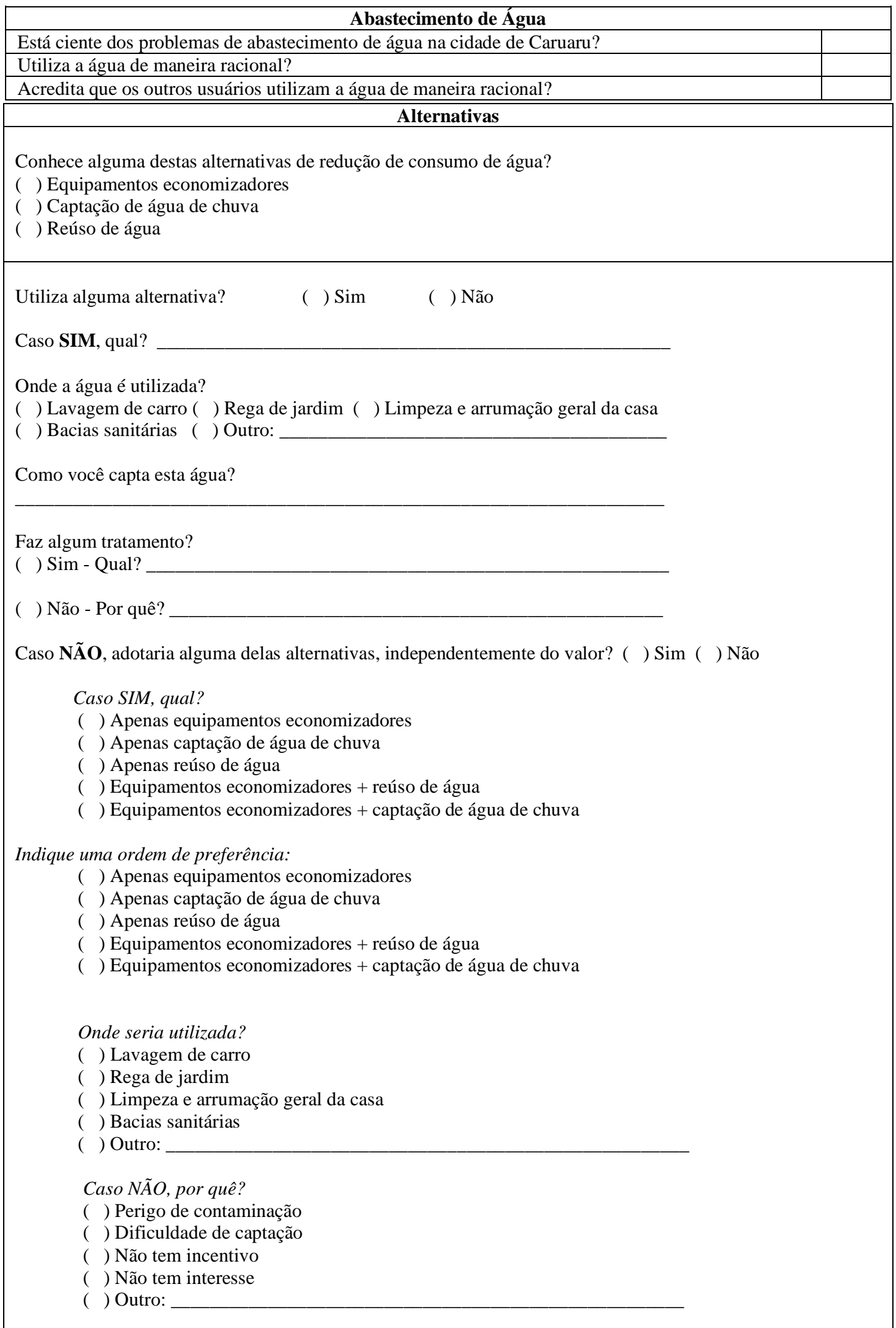

474 Sousa, L. C. O. de; Bezerra, S. de T. M.; Amorim, J. M. B. dos S.; Alves, I. M.; Duarte, A. D. 
Tabela 3 - Características dos equipamentos

\begin{tabular}{|c|c|c|c|c|c|}
\hline \multicolumn{2}{|c|}{ Equipamento convencional } & \multicolumn{3}{|c|}{ Equipamento de baixo consumo } & \multirow{2}{*}{$\begin{array}{l}\text { Quantidade de } \\
\text { equipamentos }\end{array}$} \\
\hline Tipo & $\begin{array}{l}\text { Consumo } \\
\text { médio }\end{array}$ & Tipo & Consumo médio & Preço $(\mathbf{R} \$)$ & \\
\hline $\begin{array}{c}\text { Chuveiro } \\
\text { convencional }\end{array}$ & $0,33 \mathrm{~L} / \mathrm{s}$ & $\begin{array}{l}\text { Chuveiro com } \\
\text { restritor de vazão }\end{array}$ & $0,13 \mathrm{~L} / \mathrm{s}$ & 85,00 & 1 \\
\hline $\begin{array}{c}\text { Bacia } \\
\text { sanitária } \\
\text { convencional }\end{array}$ & $\begin{array}{c}\text { 6,00 } \\
\text { L/ciclo }\end{array}$ & $\begin{array}{l}\text { Bacia sanitária com } \\
\text { acionamento duplo }\end{array}$ & 3,60 L/ciclo & 290,00 & 1 \\
\hline $\begin{array}{c}\text { Torneira } \\
\text { convencional } \\
\text { para pia }\end{array}$ & $0,42 \mathrm{~L} / \mathrm{s}$ & $\begin{array}{c}\text { Torneira de pia com } \\
\text { arejador }\end{array}$ & $0,21 \mathrm{~L} / \mathrm{s}$ & 62,00 & 1 \\
\hline $\begin{array}{c}\text { Torneira } \\
\text { convencional } \\
\text { para lavabo }\end{array}$ & $0,13 \mathrm{~L} / \mathrm{s}$ & $\begin{array}{c}\text { Torneira de lavabo } \\
\text { com arejador }\end{array}$ & $0,065 \mathrm{~L} / \mathrm{s}$ & 78,00 & 1 \\
\hline
\end{tabular}

Tabela 4 - Distribuição dos consumos de uma residência

\begin{tabular}{c|c}
\hline Uso da água & Porcentagem \\
\hline Bacia sanitária & $27,70 \%$ \\
Lavagem de roupas & $20,90 \%$ \\
Chuveiros & $17,30 \%$ \\
Torneiras & $15,30 \%$ \\
Lavagem de pratos & $1,30 \%$ \\
Outros consumos & $17,50 \%$ \\
\hline
\end{tabular}

Fonte: Tomaz (2001).

O portal HidroWeb do Sistema Nacional de Informações de Recursos Hídricos (SNIRH) da Agência Nacional de Águas (ANA) foi empregada para obtenção das precipitações médias mensais. A série histórica de precipitações mensais corresponde ao período de 2001 a 2015 (Tabela 5), e é referente à estação pluviométrica mais próxima ao residencial Caruá (Código 835106 - Alto do Moura, Caruaru, PE). Todo o volume de água captado foi direcionado, sem tratamento, para a descarga de bacias sanitárias (uso não potável).

Seguindo proposição de Nour et al. (2006), o sistema de tratamento proposto é constituído de tanque séptico seguido de filtro de areia. Essa proposta foi construída em uma residência de Florianópolis, SC, o que possibilitou a verificação do gerenciamento de esgoto em uma situação real. O projeto prevê o tratamento de água para os reúsos previstos na NBR 13969 (ABNT, 1997), indicando a redução de consumo pelo volume de recirculação das águas servidas do chuveiro e da máquina de lavar para a bacia sanitária. Em termos gerais, essas águas podem ser definidas como Classe 3, que devem apresentar parâmetros como turbidez, inferior a 10, e coliformes fecais, inferiores a $500 \mathrm{NPM} / 100 \mathrm{ml}$. O projeto atendeu as diretrizes das seguintes normas técnicas da ABNT:

(a) NBR 5626 - Instalação predial de água fria (ABNT, 1998);

(b) NBR 8160 - Sistemas prediais de esgoto sanitário-projeto e execução (ABNT, 1999); e

(c) NBR 13969 - Tanques sépticos - unidades de tratamento complementar e disposição final dos efluentes líquidos - projeto, construção e operação (ABNT, 1997).

\section{Critério 2: tempo de retorno do investimento}

A análise do critério econômico para cada alternativa foi realizada por meio do tempo de retorno do investimento (payback) descontado. O tempo de retorno descontado é o período de tempo (meses ou anos) necessário para recuperar o investimento, considerando os efeitos de composição de juros do mercado durante a análise do projeto, ou seja, indica quanto tempo é necessário para que os benefícios se igualem aos investimentos. A taxa de juros adotada foi a Selic correspondente ao mês de janeiro de 2017 (12,9\% a.a.). Os benefícios foram definidos como a diferença entre os valores da conta de água das residências sem e com a 
implementação das alternativas. A Tabela 6 exibe as tarifas adotadas pela Companhia Pernambucana de Saneamento (Compesa) em 2017.

\section{Critério 3: facilidade de implantação}

A especificação do critério técnico foi baseada nos seguintes itens: necessidade de alterações nas instalações originais da residência, necessidade de mão de obra especializada e tempo para implantação do sistema. Desse modo, o índice será a soma dos valores atribuídos em cada um dos subíndices (ver Tabela 7), que foram determinados de forma empírica com base na experiência dos autores.

\section{Critério 4: aceitabilidade geral}

O índice de aceitabilidade geral de cada alternativa pela população foi obtido por meio da aplicação de questionário a 20 residentes do residencial. O questionário está descrito no Quadro 1. O índice variou entre 0 e 1 , conforme a Tabela 8 .

Tabela 5 - Precipitação mensal (em milímetros) em Caruaru, PE, de 2001 a 2015

\begin{tabular}{|c|c|c|c|c|c|c|c|c|c|c|c|c|c|c|c|c|}
\hline \multirow{2}{*}{ Mês } & \multicolumn{15}{|c|}{ Ano } & \multirow{2}{*}{ Média } \\
\hline & 2015 & 2014 & 2013 & 2012 & 2011 & 2010 & 2009 & 2008 & 2007 & 2006 & 2005 & 2004 & 2003 & 2002 & 2001 & \\
\hline Jan & 2,9 & 7,1 & 8,7 & 29,7 & 45,5 & 117,2 & 40,2 & 46,5 & 48,5 & 4,4 & 1,4 & 261,8 & 17,0 & 149,7 & 5,0 & 52,3 \\
\hline $\mathrm{Fev}$ & 4,2 & 14,1 & 0,5 & 10,4 & 31,1 & 43,7 & 73,5 & 24,0 & 59,2 & 45,0 & 8,9 & 149,7 & 28,9 & 56,2 & 0,5 & 36,6 \\
\hline Mar & 32,3 & 45,9 & 10,8 & 26,6 & 35,7 & 14,6 & 57,8 & 133,1 & 144,8 & 11,0 & 14,9 & 70,7 & 66,9 & 54,9 & 148,5 & 57,9 \\
\hline Abr & 1,5 & 44,5 & 63,9 & 7,1 & 60,6 & 78,4 & 89,4 & 116,0 & 32,5 & 53,0 & 102,6 & 82,8 & 12,6 & 10,3 & 32,2 & 52,4 \\
\hline Mai & 18,2 & 69,6 & 12,6 & 32,8 & 126,9 & 6,7 & 181,2 & 91,3 & 44,1 & 52,0 & 114,6 & 50,1 & 42,1 & 115,9 & 5,9 & 64,2 \\
\hline Jun & 99,8 & 59,0 & 61,4 & 64,4 & 30,0 & 289,8 & 75,6 & 48,5 & 75,9 & 98,0 & 162,9 & 121,6 & 61,8 & 131,3 & 142,1 & 101,4 \\
\hline Jul & 89,0 & 47,7 & 92,6 & 0,0 & 59,7 & 50,1 & 113,8 & 81,7 & 29,6 & 0,3 & 47,1 & 90,9 & 43,5 & 39,1 & 142,1 & 61,8 \\
\hline Ago & 24,3 & 47,9 & 34,5 & 0,0 & 12,6 & 36,5 & 61,4 & 44,9 & 93,0 & 28,6 & 42,6 & 29,0 & 35,1 & 41,6 & 51,3 & 38,8 \\
\hline Set & 8,3 & 70,2 & 11,3 & 4,5 & 17,1 & 28,7 & 1,9 & 15,9 & 38,3 & 15,3 & 7,7 & 25,1 & 28,2 & 9,9 & 6,9 & 19,2 \\
\hline Out & 4,0 & 46,5 & 12,9 & 0,7 & 5,6 & 3,3 & 0,0 & 1,0 & 1,7 & 3,7 & 6,2 & 0,0 & 8,8 & 13,8 & 43,4 & 10,1 \\
\hline Nov & 1,1 & 6,6 & 39,4 & 0,7 & 15,1 & 0,0 & 12 & 0,0 & 8,4 & 1,4 & 0,0 & 0,0 & 0,0 & 13,9 & 7,8 & 7,0 \\
\hline Dez & 41,9 & 2,9 & 17,3 & 1,2 & 0,0 & 3,5 & 42,8 & 1,5 & 6,0 & 4,8 & 140,3 & 0,0 & 6,2 & 1,7 & 21,8 & 19,4 \\
\hline
\end{tabular}

Fonte: Portal HidroWeb (SISTEMA..., 2017).

Tabela 6 - Tarifa de cobrança de consumo de água da Compesa

\begin{tabular}{c|c}
\hline Consumo (L/mês) & Valor (R\$) \\
\hline Inferior ou igual a 10.000 & 40,18 \\
10.001 a 20.000 & 4,61 \\
20.001 a 30.000 & 5,48 \\
30.001 a 50.000 & 7,54 \\
50.001 a 90.000 & 8,93 \\
\hline
\end{tabular}

Tabela 7 - Índice de facilidade de implantação

\begin{tabular}{l|c|c|c}
\hline \multicolumn{1}{c|}{ Especificação } & Regra & Facilidade & Subíndice \\
\hline \multirow{2}{*}{ Mão de obra especializada } & Não necessita & Alta & 0,25 \\
& Necessita & Baixa & 0,00 \\
\hline Alterações nas instalações da & Não necessita & Alta & 0,25 \\
residência & Necessita & Baixa & 0,00 \\
\hline \multirow{2}{*}{ Tempo necessário para } & $<1$ dia & Alta & 0,50 \\
implantação do sistema & $>1$ dia e $<1$ semana & Média & 0,25 \\
& $>1$ semana & Baixa & 0,00 \\
\hline
\end{tabular}

476 Sousa, L. C. O. de; Bezerra, S. de T. M.; Amorim, J. M. B. dos S.; Alves, I. M.; Duarte, A. D. 
Tabela 8 - Índice de aceitabilidade geral

\begin{tabular}{c|c|c}
\hline Especificação & Categoria & Índice \\
\hline$<20 \%$ & Muito ruim & 0,00 \\
$\geq 20 \%$ e $<40 \%$ & Ruim & 0,25 \\
$\geq 40 \%$ e $<60 \%$ & Regular & 0,50 \\
$\geq 60 \%$ e $<80 \%$ & Boa & 0,75 \\
$\geq 80 \%$ & Muito boa & 1,00 \\
\hline
\end{tabular}

\section{Resultados e discussões}

O consumo de água total da residência foi de 468 litros por dia, determinado considerando um consumo per capita de 117 L/hab./dia, de acordo com dados do Diagnóstico dos Serviços de Água e Esgotos para a cidade de Caruaru, PE (SISTEMA..., 2018), e uma população de 4 pessoas por residência (2 pessoas por quarto). O consumo adotado é semelhante aos valores para residências de baixa renda encontrados em outros estudos realizados no Brasil (ROCHA; BARRETO; IOSHIMOTO, 1998; DANTAS et al., 2006; YWASHIMA et al., 2006; VIEIRA, 2012; GHISI et al., 2015).

\section{Alternativa 1: equipamentos economizadores}

De acordo com as informações obtidas, obteve-se a redução de consumo de água potável decorrente da implantação de equipamentos poupadores, conforme a Tabela 9. O emprego desses equipamentos em conjunto (bacia sanitária com acionamento duplo, chuveiro com restritor de vazão, torneiras com arejadores) permitiria poupar um total de $29,11 \%$ do volume fornecido pela concessionária, que representa uma economia de 136,23 litros por dia sobre um consumo diário de 468 litros por dia para cada residência. Essa redução de consumo corresponde a uma economia anual equivalente a $\mathrm{R} \$ 405,16$, com tempo de retorno do investimento de 1 ano e 4 meses.

Por meio do questionário aplicado aos moradores da região foi possível estabelecer um índice de aceitabilidade geral de 0,78 . Com relação à facilidade de implantação, pode-se inferir que a instalação dos equipamentos economizadores é bastante simples, de modo que pode ser realizada pelo próprio morador, inclusive sem necessidade de alterações na edificação. Com isso, o índice de facilidade de implantação foi 1,00. A Tabela 10 expressa o desempenho dessa alternativa para cada critério.

\section{Alternativa 2: captação de água de chuva}

O potencial de economia de água potável proporcionado pelo sistema de captação de água de chuva foi de $15,73 \%$ do consumo total, equivalente a uma economia anual de $26,88 \mathrm{~m}^{3}$ de $170,82 \mathrm{~m}^{3}$ para o padrão de consumo adotado. $\mathrm{O}$ sistema seria suficiente para abastecer o volume total requerido pela bacia sanitária apenas nos meses de junho e julho (Figura 7). Conforme destacado por Marinoski e Ghisi (2018), a implantação de ações para uso racional da água em residências de baixo padrão mostra-se um desafio, pois nessas habitações a menor relação entre a área de cobertura e o número de moradores limita o uso de água pluvial.

O potencial de economia de água foi semelhante aos estudos brasileiros realizados em habitações de baixa renda no Brasil, como os estudos de Cohim, Garcia e Kiperstok (2008), com potencial de economia de água igual a 13\% da demanda residencial; Moruzzi, Oliveira e Carvalho (2008), com 14\%; e Chaib et al. (2015), com $12,3 \%$. De acordo com o esperado, a economia estimada foi inferior à obtida por estudos realizados em regiões com maiores índices pluviométricos, por exemplo, Marinoski e Ghisi (2018), que obteve um potencial de economia de água potável de $27 \%$ em residências de baixo padrão em Florianópolis, SC.

Considerando os valores cobrados pela Compesa (Tabela 6) e o custo para a implantação do sistema de captação de água de $\mathrm{R} \$ 2.566,56$, o tempo de retorno do investimento descontado é de 24,67 anos para uma economia anual de $\mathrm{R} \$ 105,75$. O orçamento detalhado do sistema é apresentado na Tabela 11. Corroborando com os resultados, Cáceres (2018) concluiu que o uso de água de chuva não é economicamente viável em residências de baixa renda de Brasília, DF.

Por meio do questionário aplicado aos moradores da região foi possível estabelecer um índice de aceitabilidade geral para a captação de água da chuva de 0,77 . Para implantação do sistema de captação de água de chuva é necessário emprego de mão de obra especializada bem como a realização de alterações na 
edificação. A Tabela 12 mostra os parâmetros para a definição da facilidade de implantação. A Tabela 13 expressa o desempenho do sistema de captação de água de chuva para cada critério.

\section{Alternativa 3: reúso de águas cinza}

Embora o volume de água advindo do sistema de reúso de água cinza seja de 38,20\% (soma das águas do chuveiro e da máquina de lavar roupa), a redução de consumo de água potável é estabelecida pelo volume utilizado nas bacias sanitárias, que é de $27,7 \%$ do consumo total. O potencial de economia de água do sistema de reúso foi semelhante ao apresentado por Ghisi e Oliveira (2007), e superior aos valores encontrados por Marinoski e Ghisi (2019), que determinaram um potencial de economia de água igual a 19,4\% do consumo total de água em 48 habitações de baixa renda localizadas em Florianópolis, SC.

A implantação do sistema de reúso de águas cinza é a alternativa mais complexa, sendo necessário o emprego de mão de obra especializada e a realização de alterações na edificação, o que demanda tempo maior que uma semana para finalização das intervenções. Com isso, o índice de facilidade de implantação foi 0 (zero). Por meio do questionário aplicado aos moradores da região foi possível estabelecer um índice de aceitabilidade geral de 0,74. Como o custo total de implantação do sistema é R \$4.734,00 (o orçamento detalhado do sistema está apresentado na Tabela 14) e a economia anual equivale a $\mathrm{R} \$ 388,27$, o tempo de retorno do investimento é de 12,30 anos. A Tabela 15 expressa o desempenho do sistema de reúso de águas cinza para cada critério.

Tabela 9 - Consumo médio de água dos equipamentos

\begin{tabular}{l|c|c|l|c|c}
\hline \multicolumn{2}{c|}{ Equipamento convencional } & \multicolumn{2}{c}{ Tquipamento economizador } \\
\hline Tipo & Consumo médio residencial & \multicolumn{2}{c}{ Tipo } & \multicolumn{2}{c}{ Economia } \\
\hline Bacia sanitária & $27,70 \%$ & $129,64 \mathrm{~L} /$ dia & $\begin{array}{l}\text { Bacia sanitária com } \\
\text { acionamento duplo }\end{array}$ & $40 \%$ & $51,85 \mathrm{~L} / \mathrm{dia}$ \\
\hline Chuveiro & $17,30 \%$ & $80,96 \mathrm{~L} / \mathrm{dia}$ & $\begin{array}{l}\text { Chuveiro com restritor } \\
\text { de vazão }\end{array}$ & $60 \%$ & $48,58 \mathrm{~L} / \mathrm{dia}$ \\
\hline Torneira & $15,30 \%$ & $71,60 \mathrm{~L} / \mathrm{dia}$ & Torneira com arejador & $50 \%$ & $35,80 \mathrm{~L} / \mathrm{dia}$ \\
\hline Total & $\mathbf{6 0 , 3 0 \%}$ & $\mathbf{2 8 2 , 2 0} \mathrm{L} /$ dia & Total & $\mathbf{2 9 , 1 1 \%}$ & $\mathbf{1 3 6 , 2 3} \mathbf{L} /$ dia \\
\hline
\end{tabular}

Tabela 10 - Resumo dos parâmetros para os equipamentos economizadores

\begin{tabular}{l|l|c}
\hline \multicolumn{1}{c|}{ Critério } & \multicolumn{1}{|c}{ Subcritério } & Equipamentos economizadores \\
\hline Ambiental & Redução do consumo de água potável & $29,11 \%$ \\
Econômico & Tempo de retorno & 1 ano e 4 meses \\
Social & Aceitabilidade geral & 0,78 \\
Técnico & Facilidade de implantação & 1,00 \\
\hline
\end{tabular}

Figura 7 - Consumo de água não potável sem intervenção, potencial de reservação mensal e volume de água poupada pelo sistema de captação de água de chuva

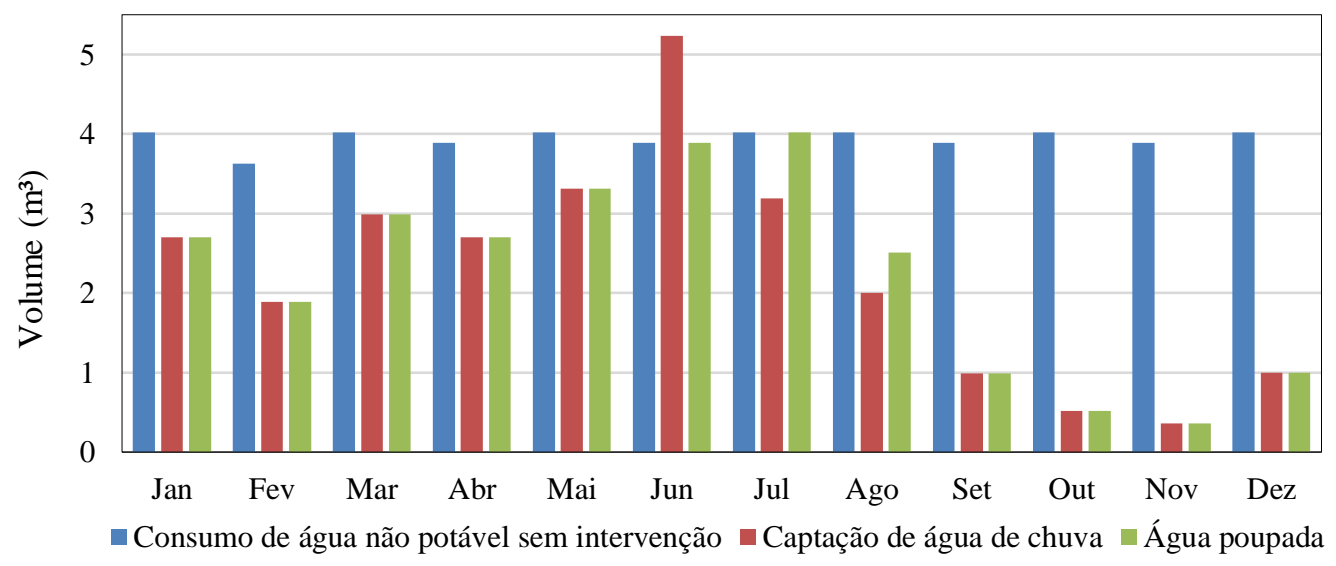

478 Sousa, L. C. O. de; Bezerra, S. de T. M.; Amorim, J. M. B. dos S.; Alves, I. M.; Duarte, A. D. 
Tabela 11 - Orçamento do projeto de sistema de captação de água de chuva

\begin{tabular}{c|l|c|c|c|c}
\hline \multicolumn{1}{|c|}{ Descrição } & Qtd. & Und. & $\begin{array}{c}\text { Valor } \\
\text { unitário }\end{array}$ & $\begin{array}{c}\text { Valor } \\
\text { Total }\end{array}$ \\
\hline C & $\begin{array}{l}\text { Calha pluvial de PVC, diâmetro entre 100 mm e 170 } \\
\text { mm }\end{array}$ & 6 & $\mathrm{~m}$ & 39,18 & 235,08 \\
\hline C & Joelho 90, PVC, DN 100 mm & 4 & und. & 6,19 & 24,76 \\
\hline C & Tubo PVC, água pluvial, DN 100 mm & 1 & und. & 40,00 & 40,00 \\
\hline D & Cola para PVC & 2 & und. & 2,00 & 6,00 \\
\hline D & Joelho 90 , PVC, DN 100 mm & 4 & und. & 6,19 & 24,76 \\
\hline D & Redução excêntrica, PVC, DN 100 mm x 50 mm & 1 & und. & 8,00 & 8,00 \\
\hline D & Registro de esfera, PVC, soldável, DN 50 mm & 1 & und. & 17,9 & 17,90 \\
\hline D & Tê, PVC, série normal, DN 100 mm x 100 mm & 9 & und. & 16,9 & 152,10 \\
\hline D & Tubo PVC, água pluvial, DN 100 mm & 4 & und. & 40,00 & 160,00 \\
\hline B & Chave de boia automática & 2 & und. & 71,30 & 142,60 \\
\hline B & Joelho 90 soldável, PVC, DN 25 mm & 6 & und. & 4,12 & 24,72 \\
\hline B & Conjunto motor-bomba 1/3 cv & 1 & und. & 379,00 & 379,00 \\
\hline B & Reservatório de polietileno de 1.000 L & 1 & und. & 300,00 & 300,00 \\
\hline B & Válvula de pé com crivo & 1 & und. & 53,62 & 53,62 \\
\hline B & Válvula de retenção & 1 & und. & 51,06 & 51,06 \\
\hline B & Tubo soldável, PVC, DN 25 mm & 6 & und. & 14,94 & 89,64 \\
\hline D & Joelho 90 soldável, PVC, DN 25 mm & 3 & und. & 4,12 & 12,36 \\
\hline D & Ponto de consumo terminal de água fria & 1 & und. & 95,18 & 95,18 \\
\hline D & Reservatório de polietileno de 500 L & 1 & und. & 170,00 & 200,00 \\
\hline D & Tubo soldável, PVC, DN 25 mm & 3 & und. & 14,94 & 44,82 \\
\hline M & Mão de obra & 16 & h & 31,56 & 504,96 \\
\hline Total & R\$ 2.566,56 & \\
\hline
\end{tabular}

Nota: valores obtidos em lojas de construção civil, e tabelas de insumos e composições do SINAPI/PE - janeiro/2017. Legenda:
C - Captação;
D - DesviUFPE;
B - Bombeamento;
D - Distribuição;
M - Mão de obra.

Tabela 12 - Facilidade de implantação do sistema de captação de água de chuva

\begin{tabular}{|c|c|c|}
\hline Especificação & Regra & Subíndice \\
\hline Necessidade de mão de obra & Necessita & 0,00 \\
\hline Alterações na edificação & Necessita & 0,00 \\
\hline Tempo de implantação & $>1$ dia e $<1$ sem & 0,25 \\
\hline \multicolumn{2}{|c|}{ Facilidade de implantação } & 0,25 \\
\hline
\end{tabular}

Tabela 13 - Resumo dos parâmetros para o sistema de captação de água de chuva

\begin{tabular}{c|c|c}
\hline Critério & Subcritério & Captação de água de chuva \\
\hline Ambiental & Redução do consumo de água potável & $15,73 \%$ \\
Econômico & Tempo de retorno & 24,67 anos \\
Social & Aceitabilidade geral & 0,77 \\
Técnico & Facilidade de implantação & 0,25 \\
\hline
\end{tabular}


Tabela 14 - Orçamento do projeto de sistema de reúso de águas cinza

\begin{tabular}{|c|c|c|c|c|c|}
\hline & Descrição & Qtd. & Und. & $\begin{array}{c}\text { Valor } \\
\text { Unitário }\end{array}$ & $\begin{array}{l}\text { Valor } \\
\text { Total }\end{array}$ \\
\hline $\mathrm{C}$ & Caixa de inspeção em alvenaria $60 \mathrm{~cm}$ x $60 \mathrm{~cm}$ & 1 & und. & 127,11 & 127,11 \\
\hline $\mathrm{C}$ & Joelho $90^{\circ}$, PVC, serie normal, DN $40 \mathrm{~mm}$ & 1 & und. & 6,10 & 6,10 \\
\hline $\mathrm{C}$ & Joelho $90^{\circ}$, PVC, serie normal, DN $50 \mathrm{~mm}$ & 1 & und. & 8,90 & 8,90 \\
\hline $\mathrm{C}$ & Tubo PVC, serie normal, DN $40 \mathrm{~mm}$ & 0,5 & $\mathrm{~m}$ & 10,38 & 5,19 \\
\hline $\mathrm{C}$ & Tubo PVC, serie normal, DN $50 \mathrm{~mm}$ & 0,5 & $\mathrm{~m}$ & 12,84 & 6,42 \\
\hline $\mathrm{C}$ & Tubo PVC, serie normal, DN $75 \mathrm{~mm}$ & 2,2 & $\mathrm{~m}$ & 27,40 & 60,28 \\
\hline $\mathrm{T}$ & Camada de areia & 1,15 & $\mathrm{~m}^{3}$ & 90,27 & 103,81 \\
\hline $\mathrm{T}$ & Camada de brita & 0,25 & $\mathrm{~m}^{3}$ & 87,13 & 21,78 \\
\hline $\mathrm{T}$ & Joelho, PVC, serie normal, DN $75 \mathrm{~mm}$ x $75 \mathrm{~mm}$ & 1 & und. & 18,61 & 18,61 \\
\hline $\mathrm{T}$ & Reservatório de polietileno de $1.500 \mathrm{~L}$ & 1 & und. & 600,00 & 600,00 \\
\hline $\mathrm{T}$ & Reservatório de polietileno de $500 \mathrm{~L}$ & 1 & und. & 170,00 & 170,00 \\
\hline $\mathrm{T}$ & Tubo, PVC, série normal, DN 75 mm x 75 mm & 3 & $\mathrm{~m}$ & 27,40 & 82,20 \\
\hline $\mathrm{B}$ & Chave de boia automática & 2 & und. & 71,30 & 142,60 \\
\hline $\mathrm{B}$ & Joelho $90^{\circ}$ soldável, PVC, DN $25 \mathrm{~mm}$ & 6 & und. & 4,12 & 24,72 \\
\hline $\mathrm{B}$ & Conjunto motor-bomba $1 / 3 \mathrm{cv}$ & 1 & und. & 379,00 & 379,00 \\
\hline $\mathrm{B}$ & Registro esfera, PVC, soldável, DN 25 mm & 1 & und. & 18,12 & 18,12 \\
\hline $\mathrm{B}$ & Reservatório de polietileno de $500 \mathrm{~L}$ & 1 & und. & 170,00 & 170,00 \\
\hline $\mathrm{B}$ & Tubo soldável, PVC, DN $25 \mathrm{~mm}$ & 10 & und. & 14,94 & 140,94 \\
\hline $\mathrm{B}$ & Válvula de pé com crivo & 1 & und. & 53,62 & 53,62 \\
\hline $\mathrm{B}$ & Válvula de retenção & 1 & und. & 51,06 & 51,06 \\
\hline $\mathrm{D}$ & Joelho $90^{\circ}$ soldável, PVC, DN $25 \mathrm{~mm}$ & 3 & und. & 4,12 & 24,72 \\
\hline $\mathrm{D}$ & Tubo soldável, PVC, DN $25 \mathrm{~mm}$ & 3 & und. & 14,94 & 44,82 \\
\hline $\mathrm{D}$ & Ponto de consumo terminal de água fria & 1 & und. & 95,18 & 95,18 \\
\hline M & Mão de obra & 48 & $\mathrm{~h}$ & 31,56 & $1.514,88$ \\
\hline $\mathrm{M}$ & Escavação manual & 6 & $\mathrm{~m}^{3}$ & 143,99 & 863,94 \\
\hline \multicolumn{2}{|c|}{ Total } & \multicolumn{4}{|c|}{$\mathrm{R} \$ 4.734,00$} \\
\hline
\end{tabular}

Nota: valores obtidos em lojas de construção civil, e tabelas de insumos e composições do SINAPI/PE - janeiro/2017. Legenda:
C - Captação;
D - DesviUfPE;
B - Bombeamento;
D - Distribuição; e
M - Mão de obra.

Tabela 15 - Resumo dos parâmetros para o sistema de reúso de águas cinza

\begin{tabular}{c|c|c}
\hline Critério & Subcritério & Reúso de águas cinza \\
\hline Ambiental & Redução do consumo de água potável & $27,70 \%$ \\
Econômico & Tempo de retorno & 12,30 anos \\
Social & Aceitabilidade geral & 0,74 \\
Técnico & Facilidade de implantação & 0,00 \\
\hline
\end{tabular}

Apesar do baixo desempenho, o reúso de água cinza, conforme destacado por Fiori, Fernandes e Pizzo (2006), contribui significativamente para a sustentabilidade hídrica de países onde o saneamento básico é deficitário e a maioria das cidades despeja o esgoto doméstico diretamente nos rios ou a céu aberto, essa medida minimiza a quantidade de poluição lançada nos corpos hídricos.

\section{Alternativa 4: equipamentos economizadores + captação de água de chuva}

O volume poupado pela alternativa 4 corresponde a $45,73 \%$ do consumo total da residência, que equivale à economia de $18,03 \%$ proporcionada pelo uso de equipamentos chuveiro com restritor de vazão (48,58 L/dia) e torneira com arejador $(35,80 \mathrm{~L} / \mathrm{dia})$, mais $27,70 \%$ pela substituição da bacia sanitária convencional pela com acionamento duplo abastecida, que poderia ser totalmente atendida pelo sistema de captação de água de chuva. A Figura 8 apresenta os volumes mensais poupados por essa alternativa.

480 Sousa, L. C. O. de; Bezerra, S. de T. M.; Amorim, J. M. B. dos S.; Alves, I. M.; Duarte, A. D. 
A associação das alternativas reduz o consumo convencional de $170,82 \mathrm{~m}^{3}$ para $92,70 \mathrm{~m}^{3}$ por ano. Desse modo, o valor cobrado mensalmente pela concessionária passa ser a taxa mínima igual a $\mathrm{R} \$ 72,32$, o que resultaria em uma economia anual de $\mathrm{R} \$ 421,75$. O custo de implantação do sistema é dado pela soma dos custos das alternativas isoladas, nesse caso igual a $\mathrm{R} \$ 3.081,56$. Assim, o tempo de retorno do investimento é de 7,35 anos.

De forma semelhante às avaliações anteriores, a ordem de preferência foi estabelecida por meio de entrevistas, de modo que o índice de aceitabilidade geral da alternativa 4 "equipamentos economizadores + captação de água de chuva" foi de 0,62. Para as alternativas associadas, utilizou-se o menor valor do índice de facilidade de implantação, nesse caso o da captação de água de chuva, que é a igual a 0,25. A Tabela 16 expressa o desempenho dessa alternativa para cada critério.

\section{Alternativa 5: equipamentos economizadores + reúso de águas cinza}

O sistema de reúso é capaz de abastecer todo o volume de água requerido pela bacia sanitária, por isso os equipamentos economizadores considerados para uso conjunto foram apenas chuveiro e torneiras. Desse modo, temos que a redução de consumo é dada pela soma dos percentuais dos sistemas isolados, o que representa um total de $45,73 \%$ do consumo total, sendo:

(a) 18,03\%: equipamentos economizadores (chuveiros + torneiras); e

(b) 27,70\%: reúso de águas cinza.

De forma semelhante aos resultados da alternativa 4, essa associação reduz o consumo convencional de $170,82 \mathrm{~m}^{3}$ para $92,70 \mathrm{~m}^{3}$ por ano, resultando em uma economia anual de $\mathrm{R} \$ 421,75$. O custo de implantação do sistema é dado pela soma dos custos das alternativas isoladas, nesse caso igual a $\mathrm{R} \$ 4.044,88$. Assim, o tempo de retorno do investimento é de 12,55 anos.

Foi estabelecido um índice de aceitabilidade geral, por meio da aplicação do questionário aos moradores da região, igual a 0,40. De forma semelhante à análise realizada para a alternativa 4, utilizou-se o valor de menor facilidade de implantação entre as alternativas. Nesse caso, o índice foi igual ao do sistema de reúso empregado isoladamente (zero). A Tabela 17 apresenta o desempenho dessa alternativa de cada critério.

Figura 8 - Consumo de água não potável sem intervenção e volumes poupados pela alternativa 4

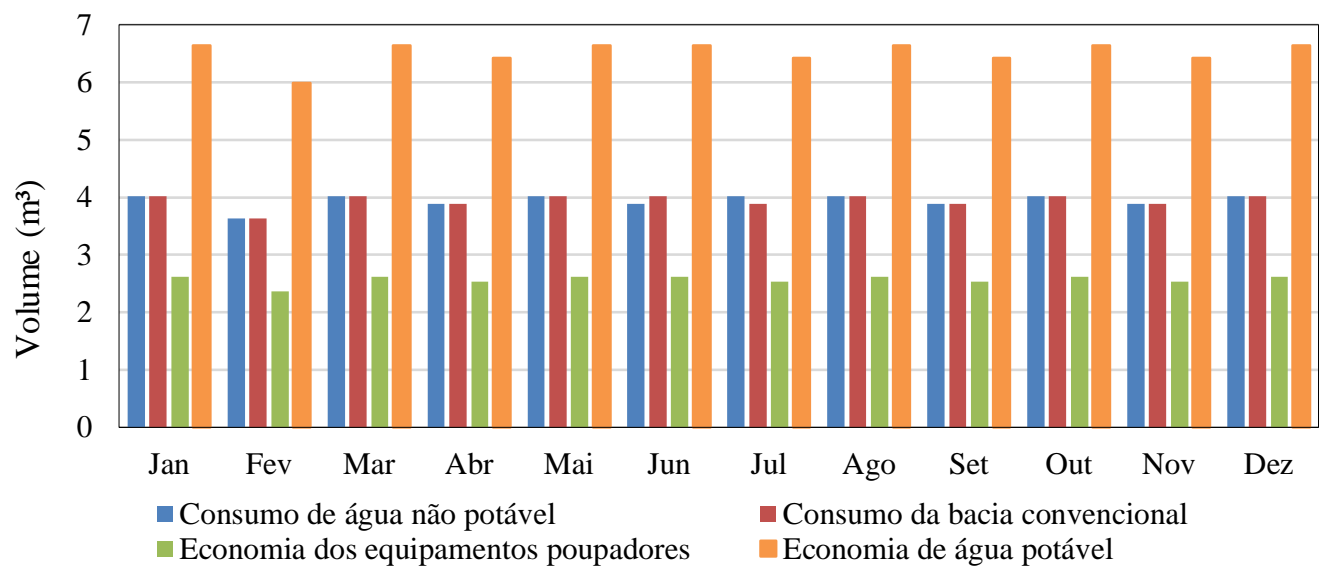

Tabela 16 - Resumo dos parâmetros para a alternativa 4

\begin{tabular}{c|c|c}
\hline Critério & Subcritério & Equipamentos + captação \\
\hline Ambiental & Redução do consumo de água potável & $45,73 \%$ \\
Econômico & Tempo de retorno & 7,35 anos \\
Social & Aceitabilidade geral & 0,62 \\
Técnico & Facilidade de implantação & 0,25 \\
\hline
\end{tabular}


Tabela 17 - Resumo dos parâmetros para a alternativa 5

\begin{tabular}{c|c|c}
\hline Critério & Subcritério & Equipamentos + reúso \\
\hline Ambiental & Redução do consumo de água potável & $45,73 \%$ \\
Econômico & Tempo de retorno & 12,55 anos \\
Social & Aceitabilidade geral & 0,40 \\
Técnico & Facilidade de implantação & 0,00 \\
\hline
\end{tabular}

Tabela 18 - Matriz de desempenho geral

\begin{tabular}{c|c|c|c|c}
\hline Alternativas & $\begin{array}{c}\text { Redução do } \\
\text { consumo de } \\
\text { água potável }\end{array}$ & $\begin{array}{c}\text { Tempo de } \\
\text { retorno } \\
\text { (anos) }\end{array}$ & $\begin{array}{c}\text { Facilidade de } \\
\text { implantação }\end{array}$ & $\begin{array}{c}\text { Aceitabilidade } \\
\text { geral }\end{array}$ \\
\hline Equipamentos economizadores & $29,11 \%$ & 1,27 & 1,00 & 0,78 \\
\hline Captação de água da chuva & $15,73 \%$ & 24,67 & 0,25 & 0,77 \\
\hline Reúso de águas cinza & $27,70 \%$ & 12,30 & 0,00 & 0,74 \\
\hline Equipamentos + captação & $45,73 \%$ & 7,35 & 0,25 & 0,62 \\
\hline Equipamentos + reúso de águas cinza & $45,73 \%$ & 12,55 & 0,00 & 0,40 \\
\hline
\end{tabular}

\section{Desempenho das alternativas}

Os dados referentes ao desempenho de cada alternativa foram organizados de modo a formar a matriz de desempenho geral do método Promethee II. Os resultados encontram-se expostos de forma resumida na Tabela 18. A Tabela 19 apresenta os resultados da análise multicritério por meio do método Promethee II. Foi determinado que o uso de equipamentos economizadores e a adoção conjunta de equipamentos economizadores e captação de água da chuva foram as alternativas mais indicadas para a redução do consumo doméstico de água potável das residências do Residencial Caruá, Caruaru, PE, apresentando os fluxos líquidos de sobreclassificação prioritários.

Os resultados da análise de sensibilidade, considerando que todos os critérios possuem o mesmo peso, são dispostos na Tabela 20, enquanto os demais, que adotaram um acréscimo de $6 \%$ no peso de cada critério e a redistribuição dos demais valores de modo que o somatório dos pesos se mantenha igual a um, são descritos na Tabela 21. Os cenários testados apontaram que o uso conjunto de equipamentos poupadores e a captação de água de chuva são as melhores alternativas, dependendo dos pesos atribuídos aos critérios.

Apesar de o estudo apontar que a implantação hipotética das alternativas tecnológicas implicaria redução significativa do consumo de água potável no padrão de residência avaliado (15,73\% a 45,73\% do consumo total), destaca-se que o Agreste Pernambucano também necessita de estratégias para o gerenciamento de fontes hídricas que resultem na geração de produtos e serviços que proporcionem um desenvolvimento econômico da região de forma sustentável.

\section{Considerações finais}

O estudo analisou alternativas tecnológicas de gerenciamento - equipamentos economizadores; captação de água de chuva; e reúso de águas cinza - como medidas direcionadas à redução do consumo de água potável em habitações de baixa renda (de interesse social) de Caruaru, PE. Essas foram avaliadas frente a quatro critérios pré-estabelecidos - redução de consumo de água potável; tempo de retorno do investimento; facilidade de implantação; e aceitabilidade geral - utilizando como instrumento de suporte à tomada de decisão o método Promethee II, e apresentando, ao final, o uso de equipamentos economizadores como medida prioritária.

Segundo as entrevistas realizadas com seis pesquisadores da Universidade Federal de Pernambuco, que possuem larga experiência na implantação das alternativas avaliadas, os critérios ambiental e econômico são os mais relevantes. Desse modo, as alternativas com melhores índices nesses critérios apresentaram, consequentemente, melhor classificação. Os índices de redução de consumo de água potável das alternativas variaram de $15,73 \%$ a $45,73 \%$, enquanto o tempo de retorno de investimento foi de aproximadamente 16 meses para a implantação dos equipamentos economizadores e superior a 7 anos para as demais alternativas. Tais resultados, do ponto de vista econômico, evidenciam a necessidade de políticas governamentais que ofereçam incentivos financeiros à população, de modo a impedir que as condições socioeconômicas da região sejam o principal entrave para a adoção de práticas de conservação dos recursos hídricos.

482 Sousa, L. C. O. de; Bezerra, S. de T. M.; Amorim, J. M. B. dos S.; Alves, I. M.; Duarte, A. D. 
Tabela 19 - Resultado da análise multicritério - Ordem de preferência

\begin{tabular}{c|c|c|c|c|c}
\hline Ranking & & Alternativa & $\mathbf{\Phi}^{+}$ & $\mathbf{\Phi}^{-}$ & Líquido \\
\hline 1 & A1 & Equipamentos economizadores & 0,6207 & 0,1850 & 0,4357 \\
2 & A4 & Equipamentos + captação & 0,5750 & 0,2514 & 0,3236 \\
3 & A5 & Equipamentos + reúso & 0,4825 & 0,3187 & 0,1638 \\
4 & A3 & Reúso de águas cinza & 0,2392 & 0,5460 & $-0,3067$ \\
5 & A2 & Captação de água de chuva & 0,1258 & 0,7421 & $-0,6164$ \\
\hline
\end{tabular}

Tabela 20 - Resultado da análise multicritério com os pesos iguais a $25 \%$

\begin{tabular}{c|c|c|c|c|c}
\hline Ranking & & Alternativa & $\boldsymbol{\Phi}^{+}$ & $\mathbf{\Phi}^{-}$ & Líquido \\
\hline 1 & A1 & Equipamentos economizadores & 0,7083 & 0,1250 & 0,5833 \\
2 & A4 & Equipamentos + captação & 0,5625 & 0,2594 & 0,3031 \\
3 & A3 & Reúso de águas cinza & 0,2328 & 0,4770 & $-0,2442$ \\
4 & A5 & Equipamentos + reúso & 0,2500 & 0,5703 & $-0,3203$ \\
5 & A2 & Captação de água de chuva & 0,2437 & 0,5656 & $-0,3219$ \\
\hline
\end{tabular}

Tabela 21 - Resultado da análise multicritério com a variação dos pesos

\begin{tabular}{|c|c|c|c|}
\hline \multirow{2}{*}{ Ranking } & \multicolumn{3}{|c|}{$\mathrm{C} 1+6 \%$} \\
\hline & Alt. & Líquido & Viabilidade \\
\hline 1 & A4 & 0,4494 & Alta \\
\hline 2 & $\mathrm{~A} 1$ & 0,2685 & Alta \\
\hline 3 & A5 & $-0,0206$ & Moderada \\
\hline 4 & A3 & $-0,1300$ & Moderada \\
\hline 5 & $\mathrm{~A} 2$ & $-0,5673$ & Baixa \\
\hline \multirow{2}{*}{ Ranking } & \multicolumn{3}{|c|}{$\mathrm{C} 2+6 \%$} \\
\hline & Alt. & Líquido & Viabilidade \\
\hline 1 & A4 & 0,4294 & Alta \\
\hline 2 & $\mathrm{~A} 1$ & 0,3910 & Alta \\
\hline 3 & A5 & $-0,1031$ & Moderada \\
\hline 4 & A3 & $-0,1475$ & Moderada \\
\hline 5 & $\mathrm{~A} 2$ & $-0,5698$ & Baixa \\
\hline \multirow{2}{*}{ Ranking } & \multicolumn{3}{|c|}{$\mathrm{C3}+6 \%$} \\
\hline & Alt. & Líquido & Viabilidade \\
\hline 1 & A4 & 0,4094 & Alta \\
\hline 2 & A1 & 0,3910 & Alta \\
\hline 3 & A5 & $-0,1406$ & Moderada \\
\hline 4 & A3 & $-0,1900$ & Moderada \\
\hline 5 & $\mathrm{~A} 2$ & $-0,4698$ & Baixa \\
\hline \multirow{2}{*}{ Ranking } & \multicolumn{3}{|c|}{$\mathrm{C} 4+6 \%$} \\
\hline & Alt. & Líquido & Viabilidade \\
\hline 1 & $\mathrm{~A} 1$ & 0,4750 & Alta \\
\hline 2 & A4 & 0,3664 & Alta \\
\hline 3 & A5 & $-0,1606$ & Moderada \\
\hline 4 & A3 & $-0,2172$ & Baixa \\
\hline 5 & $\mathrm{~A} 2$ & $-0,4636$ & Baixa \\
\hline
\end{tabular}

O estudo não "condena" as demais alternativas, mas se limita a indicar qual a mais recomendada para as condições preestabelecidas. O uso de alternativas tecnológicas é primordial no contexto estratégico do abastecimento de água urbano. Com a acentuação da escassez de água, existe maior possibilidade do aumento das tarifas de água e, assim, redução do tempo de retorno do investimento em fontes alternativas. Além disso, com o aumento do consumo nas cidades, o uso dessas fontes (por exemplo, água pluvial e reúso de águas cinza) promove redução de expansões dos sistemas existentes e, consequentemente, diminui a necessidade de novos investimentos em estações elevatórias, adutoras, redes de distribuição, etc. Assim, a 
concessionária de água ou o governo nas esferas local, estadual ou federal deveriam promover subsídios para implementação de sistemas de captação de água de chuva e/ou reúso, a fim de reduzir os gastos públicos.

\section{Limitações e recomendações}

As principais limitações desta pesquisa e recomendações para estudos futuros são:

(a) a distribuição dos consumos das residências foi adotada com base em uma única fonte bibliográfica, quando é notório que há grande variabilidade do consumo de água para a tipologia habitacional avaliada no estudo. A fim de aumentar a precisão dos resultados, o ideal seria obter dados primários das demandas de água para a classe social e região avaliada;

(b) embora não seja o foco da pesquisa, seria interessante analisar qual a aceitabilidade da população para pagar mais caro em empreendimentos que adotam fontes alternativas de água. Possivelmente, os empreendedores poderiam aumentar a margem de lucro das vendas por meio da implantação de sistemas de captação de água de chuva nas residências, que possuem baixo custo em relação ao valor do imóvel; e

(c) recomenda-se a realização de estudos voltados para o planejamento integrado de recursos hídricos na região. Esses devem considerar também a adoção de outras fontes de abastecimento, como o uso de água subterrânea. Atualmente, a Compesa está desenvolvendo, em parceria com professores do Grupo de Pesquisa Engenharia de Recursos Hídricos, Solo e Meio Ambiente (Campus Agreste - UFPE), um sistema de suporte à decisão voltado para gestão integrada de fontes hídricas do Agreste Pernambucano, que comtemplará diversos sistemas adutores e poços profundos.

\section{Referências}

ANDREOPOULOU, Z. et al. Renewable energy sources: using Promethee II for ranking websites to support market opportunities. Technological Forecasting and Social Change, v. 131, p. 31-37, 2018.

ARAÚJO, D. C. de et al. Multicriteria analysis applied to the management of urban pluvial waters. Revista Brasileira de Recursos Hídricos, v. 22, n. e18, 2017.

ASSOCIAÇÃO BRASILEIRA DE NORMAS TÉCNICAS. NBR 10844: instalações prediais de águas pluviais. Rio de Janeiro, 1989.

ASSOCIAÇÃO BRASILEIRA DE NORMAS TÉCNICAS. NBR 13969: tanques sépticos: unidades de tratamento complementar e disposição final dos efluentes líquidos: projeto, construção e operação. Rio de Janeiro, 1997.

ASSOCIAÇÃO BRASILEIRA DE NORMAS TÉCNICAS. NBR 15527: água de chuva: aproveitamento de coberturas em áreas urbanas para fins não potáveis. Rio de Janeiro, 2007.

ASSOCIAÇÃO BRASILEIRA DE NORMAS TÉCNICAS. NBR 5626: instalação predial de água fria. Rio de Janeiro, 1998.

ASSOCIAÇÃO BRASILEIRA DE NORMAS TÉCNICAS. NBR 8160: sistemas prediais de esgoto sanitário: projeto e execução. Rio de Janeiro, 1999.

BABAEI, S.; GHAZAVI, R.; ERFANIAN, M. Urban flood simulation and prioritization of critical urban sub-catchments using SWMM model and Promethee II approach. Physics and Chemistry of the Earth, v. 105, parts A/B/C, p. 3-11, 2018.

BERGER, M. et al. Amount of water needed to save $1 \mathrm{~m}^{3}$ of water: life cycle assessment of a flow regulator. Applied Water Science, v. 7, n. 3, p. 1399-1407, 2017.

BRANKOVIC, J. M.; MARKOVIC, M.; NIKOLIC, D. Comparative study of hydraulic structures alternatives using Promethee II complete ranking method. Water resources management, v. 32, n. 10, p. 3457-3471, 2018.

BRANS, J.-P. L'ingenierie de la decision, l'laboration d'instruments d'aidea la decision. In: COLLOQUE sur l'Aidea la Decision. Faculte des Sciences de l'Administration, Universite Laval, 1982.

BRANS, J.-P.; MARESCHAL, B. The Promcalc \& Gaia decision support system for multicriteria decision aid. Decision support systems, v. 12, n. 4-5, p. 297-310, 1994. 
CÁCERES, P. S. Modelo de governança de água não potável pelo aproveitamento da água pluvial e reúso de água cinza em edificações residenciais do Distrito Federal. Brasília, 2018. Dissertação de (Mestrado em Arquitetura e Urbanismo) - Pós-graduação em Arquitetura e Urbanismo, Universidade de Brasília, Brasília, 2018.

CARVALHO, J. R. S. et al. Bringing better health to those drinking rainwater in the Brazilian Semiarid: The DesviUFPE Development. In: WATER AND DEVELOPMENT CONGRESS \& EXHIBITION, Buenos Aires, 2017. Proceedings [...] Buenos Aires: International Water Association, 2017.

CHAIB, E. B. et al. Avaliação do potencial de redução do consumo de água potável por meio da implantação de sistemas de aproveitamento de água de chuva em edificações unifamiliares. Revista Brasileira de Recursos Hídricos, v. 20, n. 3, p. 605-614, 2015.

COHIM, E.; GARCIA, A. P. A.; KIPERSTOK, A. Captação e utilização de água pluvial em residências para população de baixa renda em áreas urbanas. In: SIMPÓSIO DE RECURSOS HÍDRICOS DO NORDESTE, 9., Salvador, 2008. Anais [...] Salvador, 2008.

DANTAS, C. T. et al. Caracterização do uso de água em residências de interesse social em Itajubá. In: ENCONTRO NACIONAL DE TECNOLOGIA DO AMBIENTE CONSTRUÍDO, 11., Florianópolis, 2006. Anais [...] Florianopolis, 2006.

DE KEYSER, W.; PEETERS, P. A note on the use of Promethee multicriteria methods. European Journal of Operational Research, v. 89, n. 3, p. 457-461, 1996.

FIORI, S.; FERNANDES, V. M. C.; PIZZO, H. Avaliação qualitativa e quantitativa do reúso de águas cinzas em edificações. Ambiente Construído, Porto Alegre, v. 6, n. 1, p. 19-30, jan./mar. 2006

GHISI, E. et al. Uso racional de água e eficiência energética em habitações de interesse social: volume 1: hábitos e indicadores de consumo de água e energia. Relatório de Pesquisa FINEP. Florianópolis:

Laboratório de Eficiência Energética em Edificações, 2015.

GHISI, E.; OLIVEIRA, S. M. Potential for potable water savings by combining the use of rainwater and greywater in houses in southern Brazil. Building and Environment, v. 42, n. 4, p. 1731-1742, 2007.

GOMEZ, Y. D.; TEIXEIRA, L. G. Residential rainwater harvesting: Effects of incentive policies and water consumption over economic feasibility. Resources, Conservation and Recycling, v. 127, p. 56-67, 2017.

INAMDAR, P. M. et al. Evaluation of stormwater harvesting sites using multi criteria decision methodology. Journal of Hydrology, v. 562, p. 181-192, 2018.

JUAN, Y.-K.; CHEN, Y.; LIN, J.-M. Greywater reuse system design and economic analysis for residential buildings in Taiwan. Water, v. 8, n. 11, p. 546, 2016.

KALBUSCH, A.; GHISI, E. Comparative life-cycle assessment of ordinary and water-saving taps. Journal of Cleaner Production, v. 112, p. 4585-4593, 2016.

KHORAMSHOKOOH, N. et al. Multi-objective hydraulic optimization of diversion dam's cut-off. Water Resources Management, v. 32, n. 11, p. 3723-3736, 2018.

LAFAYETTE, F. B. et al. Experimentation and modeling of soil evaporation in underground dam in a semiarid region. Revista Brasileira de Recursos Hídricos, v. 24, 2019.

MARESCHAL, B. Etude théorique et pratique des méthodes de surclassement en analyse multicritère. Mémoire Sciences Mathématiques, 1983.

MARINOSKI, A. K.; GHISI, E. Avaliação de viabilidade ambiental e econômica de sistemas de aproveitamento de água pluvial em habitação de baixo padrão: estudo de caso em Florianópolis, SC. Ambiente Construído, Porto Alegre, v. 18, n. 1, p. 423-443, jan./mar. 2018.

MARINOSKI, A. K.; GHISI, E. Environmental performance of hybrid rainwater-greywater systems in residential buildings. Resources, Conservation and Recycling, v. 144, p. 100-114, 2019.

MARQUES, J.; CUNHA, M.; SAVIĆ, D. Ranking alternatives for the flexible phased design of water distribution networks. Procedia Engineering, v. 186, p. 567-575, 2017.

MORKUNAITE, Z. et al. Contractor selection for renovation of cultural heritage buildings by Promethee method. Archives of Civil and Mechanical Engineering, v. 19, n. 4, p. 1056-1071, 2019. 
MORUZZI, R. B.; OLIVEIRA, S. C.; CARVALHO, G. Volume do reservatório de aproveitamento de água pluvial baseado no conceito do balanço de vazões para uma residência unifamiliar. Publicatio UEPG Ciências Exatas e da Terra, Ciências Agrárias e Engenharias, v. 14, n. 3, p. 212-217, 2008.

NOUR, E. A. A. et al. Gerenciamento de águas negras e amarelas: uso racional da água em edificações. Rio de Janeiro: PROSAB, 2006.

POLAT, G. et al. Urban renewal project selection using the integration of AHP and Promethee approaches. Procedia Engineering, v. 164, p. 339-346, 2016.

ROCHA, A. L.; BARRETO, D.; IOSHIMOTO, E. Caracterização e monitoramento do consumo predial de água. Programa Nacional de Combate ao Desperdício de Água, Ministério do Planejamento e Orçamento, Secretaria de Política Urbana, 1998.

SANTANA, R. A. et al. Assessing alternatives for meeting water demand: A case study of water resource management in the Brazilian Semiarid region. Utilities Policy, v. 61, p. 100974, 2019.

SAPKOTA, M. et al. Integrated evaluation of hybrid water supply systems using a Promethee-Gaia approach. Water, v. 10, n. 5, p. 610, 2018.

SEVERIS, R. M. et al. Economic analysis and risk-based assessment of the financial losses of domestic rainwater harvesting systems. Resources, Conservation and Recycling, v. 146, p. 206-217, 2019.

SHARMA, S. K.; VAIRAVAMOORTHY, K. Urban water demand management: Prospects and challenges for the developing countries. Water and Environment Journal, v. 23, n. 3, p. 210-218, 2009.

SISTEMA NACIONAL DE INFORMAÇÕES SOBRE RECURSOS HÍDRICOS. Portal HidroWeb. Brasília: Agência Nacional de Águas. Disponível em: http://www.snirh.gov.br/hidroweb. Acesso em: 03 jul. 2017.

SISTEMA NACIONAL DE INFORMAÇÕES SOBRE SANEAMENTO. Diagnóstico dos serviços de água e esgotos (ano base 2016). Brasília: Ministério das Cidades. Disponível em: http://www.snis.gov.br. Acesso em: 01 jun. 2018.

TOMAZ, P. Economia de água para empresas e residências: um estudo atualizado sobre medidas convencionais e não convencionais do uso racional da água. São Paulo: Editora Navegar, 2001.

VIEIRA, A. S. Uso racional de água em habitações de interesse social como estratégia para a conservação de energia em Florianópolis, Santa Catarina. Florianópolis, 2012. Dissertação (Mestrado em Engenharia Civil) - Pós-graduação em Engenharia Civil, Universidade Federal de Santa Catarina, Florianópolis, 2012.

VULEVIĆ, T.; DRAGOVIĆ, N. Multi-criteria decision analysis for sub-watersheds ranking via the Promethee method. International Soil and Water Conservation Research, v. 5, n. 1, p. 50-55, 2017.

WANG, X.-J. et al. Adaptation to climate change impacts on water demand. Mitigation and Adaptation Strategies for Global Change, v. 21, n. 1, p. 81-99, 2016.

WANJIRU, E.; XIA, X. Optimal energy-water management in urban residential buildings through grey water recycling. Sustainable Cities and Society, v. 32, p. 654-668, 2017.

WU, Y. et al. Social sustainability assessment of small hydropower with hesitant Promethee method. Sustainable Cities and Society, v. 35, p. 522-537, 2017.

WU, Z. et al. Developing a strategic framework for adopting water-saving measures in construction projects. Environmental Geochemistry and Health, p. 1-14, 2019.

YWASHIMA, L. A. et al. Caracterização do uso de água em residências de interesse social em Paulínia. In: ENCONTRO NACIONAL DE TECNOLOGIA DO AMBIENTE CONSTRUÍDO, 11., Florianópolis, 2006. Anais [...] Florianópolis, 2006.

\section{Agradecimentos}

Os autores agradecem à Fundação de Amparo à Ciência e Tecnologia do Estado de Pernambuco (FACEPE) e ao Conselho Nacional de Desenvolvimento Científico e Tecnológico (CNPq) pela concessão de bolsas de mestrado. 


\section{Lyanne Cibely Oliveira de Sousa}

Programa de Pós-Graduação em Engenharia Civil e Ambiental | Universidade Federal de Pernambuco | Av. Marielle Franco, Km 59, Nova Caruaru | Caruaru - PE - Brasil | CEP 55014-900 | Tel.: (81) 2103-9198 | E-mail: lyannecibely@gmail.com

\section{Saulo de Tarso Marques Bezerra}

Núcleo de Tecnologia | Universidade Federal de Pernambuco | Tel.: (81) 2103-9165 | E-mail: s.bezerra@yahoo.com.br

\section{Jose Matheus Bezerra dos Santos Amorim}

Instituto Brasileiro de Geografia e Estatística | Rua Souza Caldas, 85, Nossa Senhora das Dores | Caruaru - PE - Brasil | CEP 55002-470 | Tel.: (81) 3721-4859 | E-mail: matheus.engcivil93@gmail.com

\section{Isaura Macêdo Alves}

Programa de Pós-Graduação em Engenharia Civil e Ambiental | Universidade Federal de Pernambuco | E-mail: isauramalves@gmail.com

\section{Armando Dias Duarte}

Programa de Pós-Graduação em Engenharia Civil | Universidade Federal de Pernambuco | Av. Acadêmico Hélio Ramos, s/n, Cidade Universitária | Recife - PE - Brasil | CEP 50740-530 | Tel.: (81) 2126-8977 | E-mail: armando01.dias@gmail.com

\section{Ambiente Construído}

Revista da Associação Nacional de Tecnologia do Ambiente Construído

Av. Osvaldo Aranha, $99-3^{\circ}$ andar, Centro

Porto Alegre - RS - Brasil

$$
\text { CEP } 90035-190
$$

Telefone: +55 (51) 3308-4084

Fax: +55 (51) 3308-4054

www.seer.ufrgs.br/ambienteconstruido

E-mail: ambienteconstruido@ufrgs.br

This is an open-access article distributed under the terms of the Creative Commons Attribution License. 